\title{
Focus on PTEN regulation
}

\author{
Miriam Bermúdez Brito ${ }^{\dagger}$ Evangelia Goulielmaki ${ }^{\dagger}$ and Evangelia A. Papakonstanti*
}

Department of Biochemistry, School of Medicine, University of Crete, Heraklion, Greece

The role of phosphatase and tensin homolog on chromosome 10 (PTEN) as a tumor suppressor has been for a long time attributed to its lipid phosphatase activity against $\mathrm{PI}(3,4,5) \mathrm{P}_{3}$, the phospholipid product of the class I PI3Ks. Besides its traditional role as a lipid phosphatase at the plasma membrane, a wealth of data has shown that PTEN can function independently of its phosphatase activity and that PTEN also exists and plays a role in the nucleus, in cytoplasmic organelles, and extracellularly. Accumulating evidence has shed light on diverse physiological functions of PTEN, which are accompanied by a complex regulation of its expression and activity. PTEN levels and function are regulated transcriptionally, post-transcriptionally, and post-translationally. PTEN is also sensitive

\section{OPEN ACCESS}

Edited by:

Alexandre Arcaro,

University of Bern, Switzerland

Reviewed by:

Frederique Gaits-lacovoni, INSERM U1048, France

Saraswati Sukumar,

Johns Hopkins University, USA

*Correspondence:

Evangelia A. Papakonstanti,

Department of Biochemistry, School of Medicine, University of Crete,

Vassilika Vouton, Heraklion

GR-71003, Greece

epapak@med.uoc.gr

${ }^{\dagger}$ Miriam Bermúdez Brito and

Evangelia Goulielmaki have contributed equally to this work.

Specialty section:

This article was submitted to Molecular and Cellular Oncology, a section of the journal Frontiers in Oncology

Received: 28 May 2015 Accepted: 07 July 2015

Published: 27 July 2015

Citation:

Bermúdez Brito M, Goulielmaki E and Papakonstanti EA (2015) Focus on PTEN regulation.

Front. Oncol. 5:166. doi: 10.3389/fonc.2015.00166 to regulation by its interacting proteins and its localization. Herein, we summarize the current knowledge on mechanisms that regulate the expression and enzymatic activity of PTEN and its role in human diseases.

Keywords: PTEN, transcription, translation, protein interactions, localization

\section{Introduction}

Phosphatase and tensin homolog on chromosome 10 (PTEN) is a potent tumor suppressor gene located at chromosome 10q23.31 (1) that was discovered in 1997 (2-4). PTEN encodes a phosphatase with dual activity against phospholipids and proteins (5). PTEN protein can also regulate signal transduction pathways by both phosphatase-dependent and -independent mechanisms (6). Despite its potential tyrosine and serine/threonine phosphatase activity, the tumor-suppressor activity of PTEN is attributed to its lipid phosphatase activity (7).

Phosphatase and tensin homolog on chromosome 10 is considered the main negative regulator of class I phosphoinositide-3-kinases (PI3Ks) (8). Class IA PI3Ks are heterodimers comprised a $110-\mathrm{kDa}$ catalytic subunit ( $110 \alpha, \mathrm{p} 110 \beta$, and $\mathrm{p} 110 \delta$ ) and a regulatory $\mathrm{p} 85$ (p85 $\alpha, \mathrm{p} 55 \alpha, \mathrm{p} 50 \alpha, \mathrm{p} 85 \beta$, or p55 $\gamma$, collectively called "p85s") subunit $(9,10)$ which mediates binding to receptors, activation, and localization of the enzyme $(11,12)$. p110 $\gamma$ is the class IB PI3K, which occurs in complex with the p101 $(13,14)$ or p84 $(15,16)$ protein. PI3Ks are stimulated by a variety of signals, including growth factors and G-protein-coupled receptors (17). When activated, PI3Ks phosphorylate the 3-position of the inositol ring of the phosphatidylinositol-4,5-biphosphate ( $\left.\mathrm{PIP}_{2}\right)$ to produce the second messenger phosphatidylinositol-3,4,5-triphosphate ( $\left.\mathrm{PIP}_{3}\right)(18)$. The PI3K complex, which is recruited to the plasma membrane, then activates the pyruvate dehydrogenase kinase 1 (PDK1) and Akt (19). PTEN, through its lipid phosphatase activity, catalyzes the conversion of $\mathrm{PIP}_{3}$ to $\mathrm{PIP}_{2}$ by dephosphorylating the 3-position of the inositol ring of $\mathrm{PIP}_{3}$, antagonizing thus the PI3K signaling $(20,21)$. Consequently, PTEN blocks the activation of downstream signaling events, including PDK1/Akt and Akt/mammalian target of rapamycin (mTOR) (20). Given that PI3K regulates diverse cellular processes, including cell proliferation and survival, reduced or lost activity of PTEN contributes to the constitutive activation of the PI3K pathway (22-25). The elevated levels of $\mathrm{PIP}_{3}$ in cancer cells prevent apoptosis and moreover allow an uncontrolled cellular growth and proliferation (26). Many human cancers are associated with somatic deletions or mutations of the PTEN gene, including 
endometrial carcinoma $(27,28)$, glioblastoma multiforme (29, $30)$, skin (31), breast (32,33), and prostate cancers (34). Moreover, PTEN is being emerging as an important factor in other diseases, such as diabetes (35) and autism spectrum disorders (36).

Phosphatase and tensin homolog on chromosome 10 plays a key role as tumor suppressor, therefore maintaining a stable level of its expression seems to be critical. Studies have shown that the expression and enzymatic activity of PTEN are tightly regulated at transcriptional, post-transcriptional, and post-translational level, as well as by protein-protein interactions $(37,38)$. The understanding of how PTEN is regulated is essential for deepening our knowledge into cancer biology that could provide new strategies for cancer therapies. In this review, we go over the main insights into PTEN regulation.

\section{Transcriptional Regulation}

Phosphatase and tensin homolog on chromosome 10 promoter is positively and negatively regulated by many transcription factors that operate at specific times and in different types of cells (37) (Figure 1).

Positive regulators of PTEN gene expression include early growth response protein 1 (EGFR-1), peroxisome proliferatoractivated receptor $\gamma$ (PPAR- $\gamma$ ), and tumor protein 53 (Tp53; also known as p53). These transcription factors were shown to directly bind to PTEN promoter region (39-41). The human sprout homolog 2 (SPRY2) mediates also its anti-proliferative actions by altering PTEN content and activity (42). On the other hand, diverse negative regulators of PTEN have been reported. Indeed, the Ras/Raf/MEK/ERK pathway was shown to suppress the transcription of PTEN through c-Jun (43). Likewise, nuclear factor kappa B (NF- $\kappa \mathrm{B})$ negatively regulates PTEN expression through sequestration of the transcriptional co-activator $\mathrm{CBP} /$ p300 (44). In addition, transcription factors, such as mitogenactivated protein kinase kinase-4 (MKK4), transforming growth factor beta (TGF- $\beta$ ), and the polycomb group (PcG) protein BMI1, were reported to suppress PTEN expression in several cancer models (45-48).

Epigenetic silencing by gene promoter methylation and histone modifications has also been proposed as a mechanism by which PTEN expression can be suppressed. This mechanism of PTEN regulation has been implicated in several cancers, such as gastric, colorectal, melanoma, and breast cancer (49-52). Several studies have shown that silencing of PTEN transcription is often due to the presence of hypermethylated $\mathrm{CpG}$ islands in the PTEN promoter $(49,52)$. However, careful consideration must be taken when interpreting epigenetic silencing regarding PTEN because a PTEN-pseudogene exists with a promoter, which is also shown to be methylated (53). PTENP1 pseudogene shares $97.8 \%$ sequence identity with the PTEN mRNA sequence, and $91 \%$ identity with a 921 bp region of the PTEN CpG island. Moreover, PTEN shares a CpG island promoter with another gene known as KLLN, which is transcribed from the negative DNA strand in the opposite direction (54). Thus, methods that detect methylation but do not distinguish between PTEN and the pseudogene sequences may lead to false positives (53). In this scenario, the methylation status of regions with particularly high homology to pseudogenes can only be determined using allelic bisulfite sequencing to allow the identification of pseudogenespecific alleles $(54,55)$.

Finally, NOTCH signaling has been shown to act either as a negative or as a positive regulator of PTEN transcription. By acting through PTEN down-regulators, NOTCH signaling leads to PTEN downregulation by activating the transcription factor hairy and enhancer of split1 (HES1) (56), or conversely, to its up-regulation by inhibiting the recombining binding protein suppressor of hairless (RBPJ, also known as CBF-1) $(57,58)$.

\section{Post-Transcriptional Regulation}

MiRNAs are small and evolutionarily conserved non-coding single-stranded RNAs that negatively regulate gene expression by binding to the $3^{\prime}$-untranslated region ( $3^{\prime}$-UTR) of the target mRNAs in mammalian cells, leading to mRNA degradation or translational repression (59-61). miRNAs are thought to regulate the expression of almost all genes and consequently to play critical roles in the coordination of fundamental processes, including differentiation, proliferation, angiogenesis, death, and metabolism $(59,62,63)$. Increasing evidences have demonstrated that miRNAs play an important role in the pathogenesis, from initiation to metastasis, of many cancers by regulating proto-oncogenes or tumor-suppressor genes $(64,65)$. Moreover, miRNAs that act as tumor suppressors (e.g., miR-145, miR-124, and miR-142-3p) (66-68) or oncogenes (e.g., miR-21, miR-218, and miR-24) (69-71) have been identified in many types of tumors.

Given the importance of PTEN as a tumor suppressor (72), it is not surprising that a plethora of miRNAs have been identified to modulate PTEN expression at the post-transcriptional level (Figure 1). These miRNAs include those that contain a single harpin structure, such as miRNA-21 (73, 74), miRNA-22 (75), and miRNA-214 (76), as well as those with a polycistronic structure, such as mir-17-92 (77-79), mir-106b-25 (75), mir-367-302b (75), and mir-221-222 (74).

miR-21 is one of the most frequently aberrant miRNAs in human cancers. Upregulation of miR-21 has been reported to directly target PTEN promoting thus the growth and metastasis of specific cancers, including non-small cell lung cancer (80), colorectal carcinoma (81), ovarian cancer (82), as well as triple-negative breast cancers (83). Furthermore, Iliopoulos et al. (84) has shown that miR-21, together with miR-181b-1, inhibit PTEN and cylindromatosis (CYLD) tumor suppressor functions, respectively, leading to increased $\mathrm{NF}-\mathrm{kB}$ activity thus underlying the epigenetic switch that links inflammation to cancer. miR214 was found to induce cell survival and cisplatin resistance by direct binding to the $3^{\prime}$-UTR of PTEN leading to decreased PTEN expression and to activation of Akt signaling pathway (85). Deregulation of miR-214 has also been shown in several human tumors including breast, melanoma, and hepatocellular cancer (86). In addition, miR-93 and miR-130a may also be associated with cisplatin resistance by direct targeting PTEN in ovarian cancer cells $(87,88)$. In line with this result, an inhibitor of MiR-130a was found to reverse the cisplatin resistance by upregulating the expression of PTEN and downregulating P-glycoprotein (P-gp) in A2780 cell lines (89). 


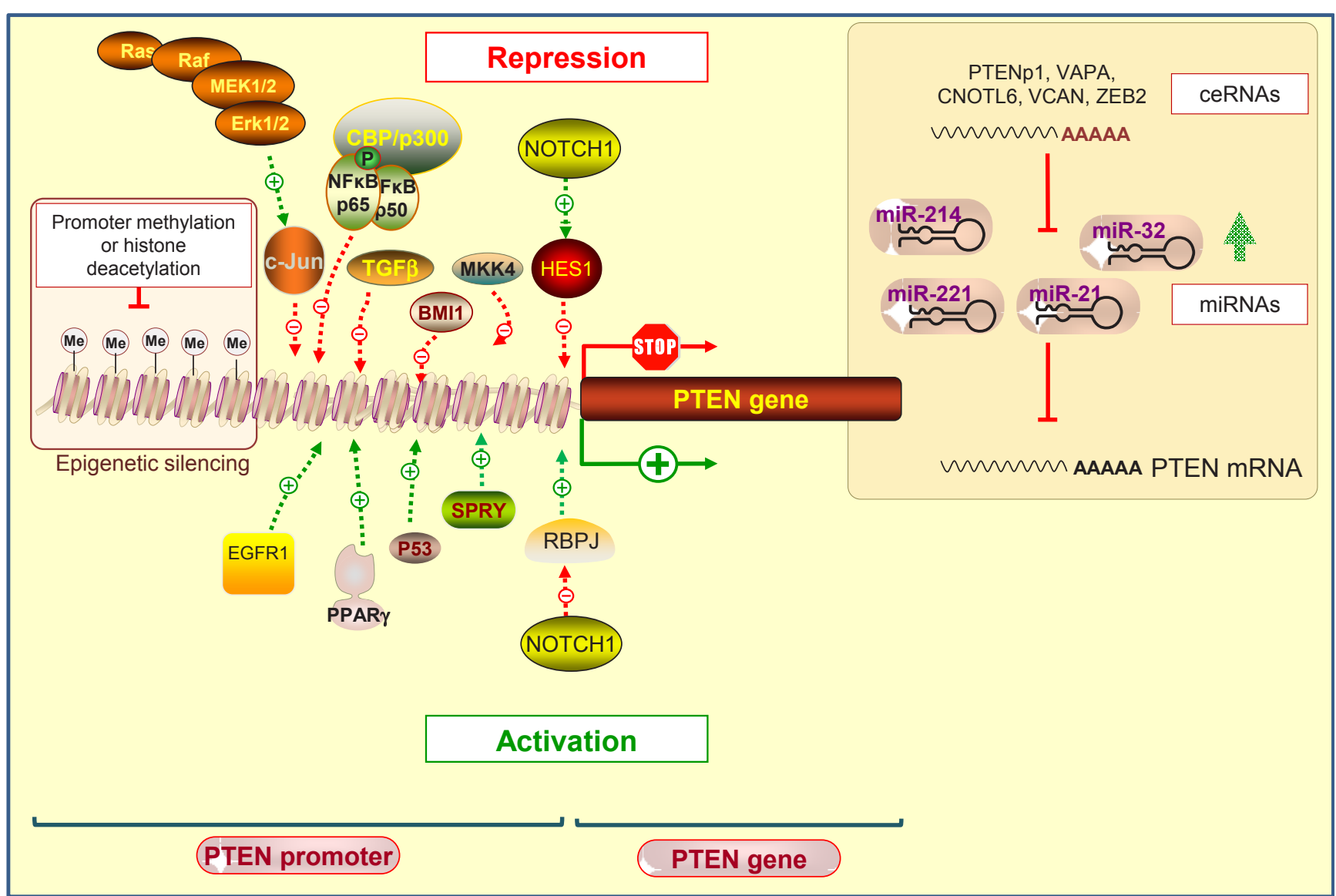

FIGURE 1 | Regulation of PTEN expression by epigenetic, transcriptional, and post-transcriptional mechanisms. Positive regulators of PTEN gene expression include early growth response protein-1 (EGFR-1), peroxisome proliferator-activated receptor- $\gamma$ (PPAR- $\gamma$ ), tumor protein 53 (Tp53; also known as p53), and human sprout homolog 2 (SPRY2). PTEN transcription can also be repressed. Several transcription factors including C-Jun, nuclear factor kappa B (NF-kB), mitogen-activated protein kinase kinase-4 (MKK4), transforming growth factor beta (TGF- $\beta$ ), and the polycomb group protein BMl1 are known to repress PTEN expression. Interestingly, it has been shown that NOTCH signaling could be either a negative or positive regulator of PTEN transcription targeting the transcription factor hairy and enhancer of split1 (HES1) or the recombining binding protein suppressor of hairless (RBPJ, also known as CBF-1), respectively. Epigenetic silencing by the gene promoter methylation and histone modifications may also negatively control PTEN expression. At the post-transcriptional level, a variety of miRNAs have been identified to repress PTEN mRNA translation. An additional level exists, involving endogenous non-coding transcripts that have regulatory functions by quenching miRNAs, such as PTENpg1 and ZEB2.
Comparable findings have also been published for other miRNAs. Recently, Xie et al. (90) reported that miR-221 targets $\mathrm{PI} 3 \mathrm{~K} / \mathrm{Akt}$ signaling axis inducing thus cell proliferation and 1,3-bis(2-chloroethyl)-1-nitrosourea) (BCNU) resistance in human glioblastoma. More specifically, the overexpression of PTEN lacking 3'-UTR or the PI3K inhibitor wortmannin was found to attenuate the miR-221-mediated BCNU resistance and to promote cell apoptosis.

The importance of PTEN regulation by miRNAs in cancer progression is highlighted in multiple occasions. Indeed, deregulation of miR-214, miP-199a*, miR-200a, and miR-100 was shown to be frequent in ovarian cancers (85). MiR-26a negatively regulates the expression of PTEN in a murine glioma model and enhances the formation of tumors de novo (91). MiR-26a also enhances lung cancer metastasis via modulation of metastasisrelated genes and PTEN inhibition (92). Similarly, Lang et al. (93) showed that miR-429 induces tumorigenesis of human non-small cell lung cancer cells by directly targeting the $3^{\prime}$-UTR of multiple tumor suppressor genes, including PTEN, RASSF8, and TIMP2. In breast cancer, PTEN is targeted by miR-29b (94) and miR-301 (95). miR-301a was also shown to directly target and suppress PTEN, maintaining constitutively activated Wnt/ $\beta$-catenin signaling, which leads to the enhancement of breast cancer invasion and metastasis (96).

High-frequency miRNA dysfunction is also associated with prostate cancer development and progression. MiR-153 promotes proliferation of human prostate cancer cells through direct suppression of PTEN expression (97). Additionally, a combination of four miRNAs (miR-19b, miR-23b, miR26a, and miR-92a) was found to regulate PTEN expression post-transcriptionally and to affect the downstream PI3K/ Akt pathway via PIK3CA (p110 $\alpha)$, PIK3CD (p1108), PIK3R1 (p85), Akt, and cyclin D1, thus promoting prostate cancer cells proliferation in vitro (98). 
The regulation of PTEN by miRNAs is also found in colorectal cancer (99). miR-92a was reported to promote cell metastasis of colorectal cancer through the PTEN-mediated PI3K/Akt pathway. Likewise, upregulated miR-494 was found to directly target the $3^{\prime}$-UTR of PTEN and this was associated with tumor aggressiveness and tumor metastasis (100). miR-103 was shown to promote colorectal cancer through downregulation of the tumor-suppressor genes DICER and PTEN (101). On the other hand, miR-32 is overexpressed in colorectal carcinoma inducing cell proliferation, migration, and invasion (102). Moreover, the expression of miR-32 was upregulated in hepatocellular carcinoma tissues and cell lines and inversely the expression of PTEN was decreased (103).

Emerging evidence has highlighted the importance of new types of RNA-RNA interactions that underlie the regulation of gene expression. It is important to note that one single miRNA can regulate multiple mRNAs of the same or different pathways and thereby a single miRNA can control an entire posttranscriptional program and influence dozens of target genes (104). Conversely, several miRNAs can regulate a single mRNA. Moreover, RNA transcripts, such as mRNAs, non-coding RNAs, pseudogene transcripts, and circular RNAs, could regulate each other by competing for the same pool of miRNAs, acting as "competing endogenous RNAs" (ceRNAs) $(105,106)$. These ceRNAs share sequences recognized by the miRNAs called microRNA recognition elements (MREs) (107). ceRNAs could sponge the miRNA through direct competition for miRNA binding and as a consequence increase the levels of endogenous miRNA targets (108). More recently, ceRNAs that take crucial roles in oncogenic pathways of many types of cancer have been called "oncocers" (109).

The first evidence that an endogenous non-coding transcript can have regulatory functions by quenching miRNAs in humans was presented by Poliseno et al. (110). PTEN expression was found to be post-transcriptionally regulated by the action of a PTEN pseudogene (PTENpg1, also known as PTENp1, PTEN2, and PTENI1) network (110). The PTENP1 locus encodes three different long non-coding RNA (lncRNA) molecules, one sense $P T E N p 1$ and two functional antisense RNAs (asRNAs) isoforms, $\alpha$ and $\beta$ (111). PTENp1 sense is an lncRNA that shares extensive sequence homology with PTEN mRNA, especially in the ORF region and within the first third of its $3^{\prime}$-UTR, a region enriched for known miRNA target sites. Thus, it functions like an miRNA sponge, sequestering them and therefore de-repressing PTEN expression and enhancing its tumor-suppressor activity. For instance, PTENp1 was found to sequester several miRNAs families that target PTEN mRNA, such as miR-17, miR-19, miR-21, miR-26, and miR-214, among others (110). An additional level of complexity in this crosstalk between miRNAs and RNAs is provided by PTENp1 antisense transcripts, which regulate PTEN expression both at the transcriptional and translational levels. PTENp1 as RNA- $\alpha$ acts in trans, localizes to the PTEN promoter, and inhibits PTEN transcription by recruiting epigenetic repressor complexes. In contrast, the $\beta$ isoform, which is partially complementary to PTENP1 sense, interacts with PTENpg1 sense through an RNA:RNA pairing interaction, which positively regulates PTEN expression, and thus promotes stabilization of
PTENp1 sense by binding to its $5^{\prime}$ end (111). PTENp1 is not the only miRNA decoy regulating PTEN expression. Other protein-coding genes, such as vesicle-associated membrane protein-associated protein A (VAPA), CCR4-NOT transcription complex, subunit 6-like (CNOT6L), or Versican (VCAN), have a similar role and act as competing RNAs for PTEN-interacting miRNAs $(112,113)$. Moreover, Karreth et al. (114) characterized ZEB2 as a bona fide PTEN ceRNA. ZEB2 acts a tumor suppressor by regulating PTEN expression through its mRNA in melanoma. The abrogation of ZEB2 expression releases the miRNAs that downregulate PTEN, cooperating with BRAF to promote melanomagenesis.

New miRNAs that are involved in PTEN regulation are still being reported and the functions of most of these miRNAs still remain to be discovered. Direct targeting of miRNAs might be a potential strategy of certain cancer treatments in the near future.

\section{Post-Translational Modifications of PTEN}

Phosphatase and tensin homolog on chromosome 10 is a 403 amino acid protein composed of four structural-functional domains (115). A PI(4,5) $\mathrm{P}_{2}$ (PIP2) binding domain (aa 1-13), a catalytic tensin-type phosphatase domain (aa 14-185), a C2 tensin-type domain, which binds phospholipids (aa 190-350), the carboxy-terminal tail of the protein (aa 350-400), and a PDZ-domain binding (aa 401-403). Modifications of amino acids in each one of the above domains interfere with protein stability, activity, interaction with other proteins, and localization (Figure 2).

\section{Phosphorylation}

Phosphatase and tensin homolog on chromosome 10 is one of the most commonly mutated tumor suppressors in human cancers. However, loss of PTEN activity in the absence of mutations appears to occur in an even greater number of tumors. This could readily be due to post-translational modifications of the phosphatase. For example, in human $\mathrm{T}$ cell acute lymphoblastic leukemia (T-ALL), increased phosphorylation of PTEN results in hyperactivation of the PI3/Akt pathway $(116,117)$. Increased levels of phosphorylated PTEN were also detected in samples from patients with gastric cancer suggesting a role in gastric carcinogenesis (118).

\section{C-Tail Phosphorylation}

The most well-studied phosphorylation events taking place in PTEN are that in the C-tail moiety of the molecule and more specifically on amino acids Ser362, Thr366, Ser370 (119, 120), and the cluster containing Ser380, Thr382, Thr383, and Ser385 $(121,122)$. The phosphorylation of the cluster is driven mainly by casein kinase 2 (CK2), as well as by S6K $(120,123)$, whereas the phosphorylation of Ser362 and Thr366 is conferred by glycogen synthase kinase $3 \beta$ (GSK3b) $(119,124)$. Thr366 and Ser370 are phosphorylated by polo-like kinase 3 (PlK3) (125) (Figure 2).

The effect of these phosphorylation events on PTEN protein function is "pluripotent." Phosphorylation of PTEN interferes with the localization, the stability, and the activity of the protein. 


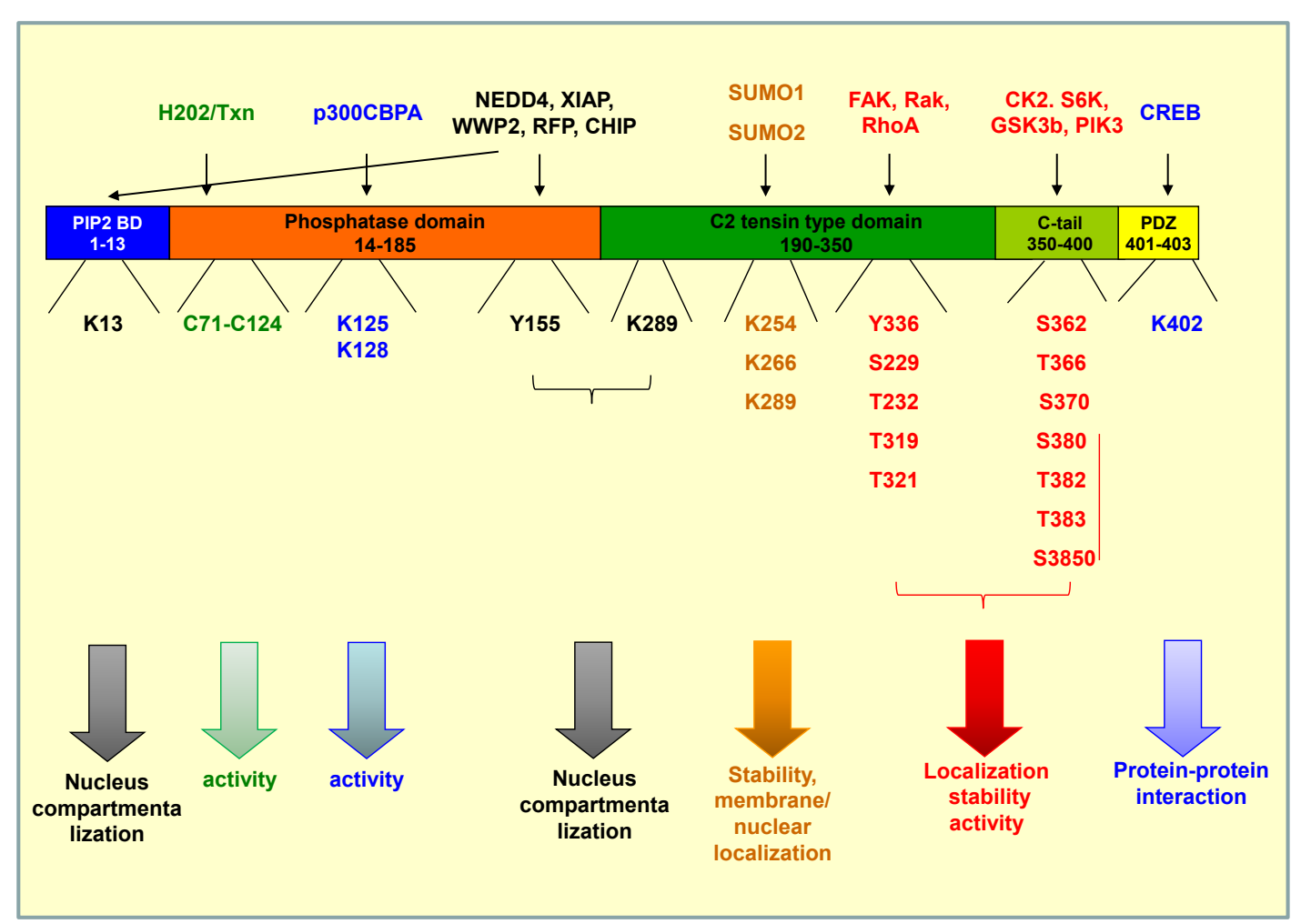

FIGURE 2 | Post-translational modifications of PTEN. PTEN is composed of four structural domains [PIP2-binding domain (aa 1-13), a catalytic tensin-type phosphatase domain (aa 14-185), a C2 tensin-type domain, which binds phospholipids (aa 190-350), the carboxy-terminal tail of the protein (aa 350-400), and a PDZ-binding domain (aa 401-403). The residues where phosphorylation (red), acetylation (blue), oxidation (green), ubiquitination (black) and sumoylation (orange) take place are indicated. The proteins conferring each modification are mentioned on the top of the figure. All modifications interfere directly or indirectly with the activity of the phosphatase by regulating also its compartmentalization and/or its stability.
C-tail phosphorylated PTEN seems to adopt a compact conformation, which does not allow the protein to interact with membrane phospholipids (126-130) or with other membrane anchored proteins, mainly PDZ-containing proteins, such as MAGI-3 (131-133). Abolishment of PTEN membrane interactions renders the phosphatase inactive against its membrane localized substrate $\mathrm{PI}(3,4,5) \mathrm{P}_{3}$. The importance of PTEN membrane anchoring has also been shown by mutations affecting the PIP2 lipid-binding domain, which also totally abrogated the PTEN function (127, 134). Recent data reveal an alternative mechanism through which PTEN phosphorylation affects dimerization and activity of the protein. More specifically, two PTEN species were identified; a dimeric unphosphorylated and a monomeric phosphorylated. The monomeric phosphorylated conformation of PTEN was shown to be essentially inactive (135). C-tail phosphorylation of PTEN was shown to affect not only the cytosol/membrane but also the cytosol/nuclear protein distribution. More specifically, phosphorylation of PTEN led to nuclear export of the protein $(123,136)$.

Interestingly, although PTEN phosphorylation negatively affects the phosphatase activity, it seems to increase the protein stability. More specifically, closed phosphorylated PTEN is less prone to ubiquitin ligases and therefore less prone to degradation in comparison to open unphosphorylated PTEN $(122,133)$.
It is of note that the phosphorylation events and their effect on protein stability and/or activity may differ according to the cell context. For instance, phosphorylation of Thr366 led to destabilization of the phosphatase in glioma cell lines but not in epithelial cell lines (124).

\section{C2 Domain Phosphorylation}

Similarly to C-tail, the C2 domain has also been shown to be phosphorylated by different kinases. RAK was shown to phosphorylate Tyr336 whereas RhoA-associated kinase (ROCK) has been shown to phosphorylate Ser229, Thr232, Thr319, and Thr321 $(137,138)$ (Figure 2 ). The activity of these kinases seems to affect also PTEN activity, localization, and stability. More specifically, Rak activity prevents the binding of PTEN to its E3 ligase NEDD4-1 thus protecting PTEN from polyubiquitination and subsequent protein degradation $(137,138)$. On the other hand, ROCK together with the Rho small GTPases, RhoA and $\mathrm{Cdc} 42$, regulates PTEN intracellular localization and PTEN-mediated chemotaxis $(137,138)$. Similarly, PTEN was found to become activated and tyrosine phosphorylated by a RhoA/ROCK-mediated mechanism, which is a part of a p1108 PI3K-induced signaling cascade that leads to the regulation of chemotaxis and cell proliferation $(139,140)$. We have also recently found that FAK phosphorylates PTEN on Tyr336 
(Figure 2) downstream of RhoA and under the negative control of p1108 PI3K (141). The phosphorylation on Tyr336 by FAK affects phosphatase activity, membrane association, and stability of PTEN protein (141).

\section{PTEN Dephosphorylation}

Dephosphorylation of PTEN is equally important for its biological functions. N-myc downstream-regulated gene 2 (NDRG2) is a PTEN-binding protein that recruits protein phosphatase $2 \mathrm{~A}$ (PP2A) to PTEN. Expression of NDRG2 is frequently downregulated in adult T-cell leukemia-lymphoma (ATLL), resulting in enhanced phosphorylation in C-tail of PTEN and enhanced activation of the PI3K-AKT pathway (117).

Apart from its lipid phosphatase activity, PTEN also has a poorly characterized protein phosphatase activity. PTEN appears to be able to dephosphorylate itself at its C-tail and C2 domain $(142,143)$. It could be that the dominant role for protein phosphatase activity of PTEN is autodephosphorylation-mediated regulation of its lipid phosphatase activity.

\section{Oxidation}

Phosphatase and tensin homolog on chromosome 10 belongs to the enzyme family of protein tyrosine phosphatases (PTP). Oxidation of several PTPs by $\mathrm{H}(2) \mathrm{O}(2)$ forms a disulfide bond between two cysteines, one in the active site (in the case of PTEN Cys 124) and another nearby (Cys71, in the case of PTEN) and followed by consequent inactivation of the enzymes. The disulfide bond likely confers efficiency in the redox regulation of the PTPs (144).

Exogenously and endogenously produced $\mathrm{H}_{2} \mathrm{O}_{2}$ were shown to oxidize and inactivate recombinant PTEN and PTEN produced in cultured macrophages (145). Mice lacking peroxidase Prdx1 produce more ROS and are prone to carcinogenesis. In these mice, Akt pathway is hyperactive and PTEN was found to be inactivated due to increased oxidation (146). Inactivation of PTEN can be reversed by reduction of $\mathrm{H}(2) \mathrm{O}(2)$-oxidized phosphatase. This step in cells appears to be mediated predominantly by thioredoxin (147). The latter was also verified by analysis of Thioredoxin-interacting protein (Txnip) knock-out mice. Txnip was shown to be required to maintain sufficient thioredoxin activity in order to reductively reactivate oxidized PTEN and oppose Akt downstream signaling (148). Surprisingly, Thioredoxin-1 was also found to bind directly to the C2 domain of PTEN leading to steric interference of its catalytic site (149).

\section{Acetylation}

Phosphatase and tensin homolog on chromosome 10 function can also be regulated by acetylation and deacetylation events. Two acetylation sites have been identified till now. One is located in the phosphatase active domain (Lys 125-128) and is conferred by p300/calcium-binding PTEN-associated factor. Acetylation of this site was reported to downregulate PTEN activity (150). The other acetylation event is driven by CREB-binding protein and results in the modulation of PTEN interaction with other PDZ-domain containing proteins (151). PTEN was also shown to be deacetylated by histone deacetylase SIRT1 resulting in enhancement of its phosphatase activity (152).

\section{Ubiquitination}

Ubiquitination is an enzyme-catalyzed cascade that is known to mark protein substrates for $26 \mathrm{~S}$ proteasome-dependent degradation by covalently conjugating them with multiple ubiquitin monomers via lysine (K)48-linkage. Furthermore, ubiquitination also alters protein localization, trafficking, and/or activation via K63-linked polyubiquitin chains. In case of PTEN, both states of mono- and poly-ubiquitinations have been reported. Polyubiquitination targets PTEN for proteasomal degradation, which also finely tunes the expression levels of the protein in the cell $(122,133)$. Mono-ubiquitination takes place at Lys13, Tyr155, and Lys289 and regulates PTEN localization in the nucleus. PTEN compartmentalization in the nucleus is a key regulator of tumor development (153). In parallel, it was shown that both poly- and mono-ubiquitination of PTEN inhibit its phosphatase activity, thus interfering also with the tumor-suppressive role of PTEN (124).

Several enzymes were found to catalyze the ubiquitination of PTEN. NEDD4 was identified as a potential ubiquitin ligase of the phosphatase in some cases $(154,155)$ but not all $(156)$, although its role in tumor development may be independent of PTEN (157). Other E3 ubiquitin ligases that found to interact with PTEN are XIAP (158), WWP2 (159), and RFP (160) as well as the chaperone-associated E3 ligase and C terminus of Hsc70interacting protein (CHIP), which also plays the role of an E3 ligase (161) (Figure 2).

Importantly, ubiquitination is a reversible state; deubiquitination is conferred by the PML-DAXX-HAUSP network and is proposed to act as an additional switch controlling PTEN activity, expression levels, and compartmentalization (162). Besides ubiquitination, another frequent post-translational modification occurring at lysine residues is SUMOylation. PTEN is modified by the small ubiquitin-like proteins, small ubiquitin-related modifier 1 (SUMO1), and SUMO2 at lysine residues 254, 266, and 289 , all of which are located in the C2 domain $(163,164)$ (Figure 2) These modifications were shown to enhance PTEN interaction with the membrane and to regulate nuclear localization (165), whereas in parallel SUMOylated PTEN is less prone to ubiquitination (163).

\section{Regulation of PTEN by Protein Interactions}

The interaction of PTEN with other protein components can lead to a series of post-translational modifications, which heavily modulate the activity of the phosphatase. Reversibly, PTEN also affects the mode of action of its interacting partners. PTEN interactomics is beginning to become delineated by different approaches, either high-throughput proteomics or targeted biochemical assays. The binding partners of PTEN can be divided in different categories. Some representative interacting partners of PTEN are shown in Figure 3.

\section{Receptors}

Sphingosine 1-phosphate (S1PR) (166) and melanocortin-1 (MC1R) (167) receptors, which are G-protein-coupled receptors as well as androgen receptor (AR), which is a nuclear receptor (168), 


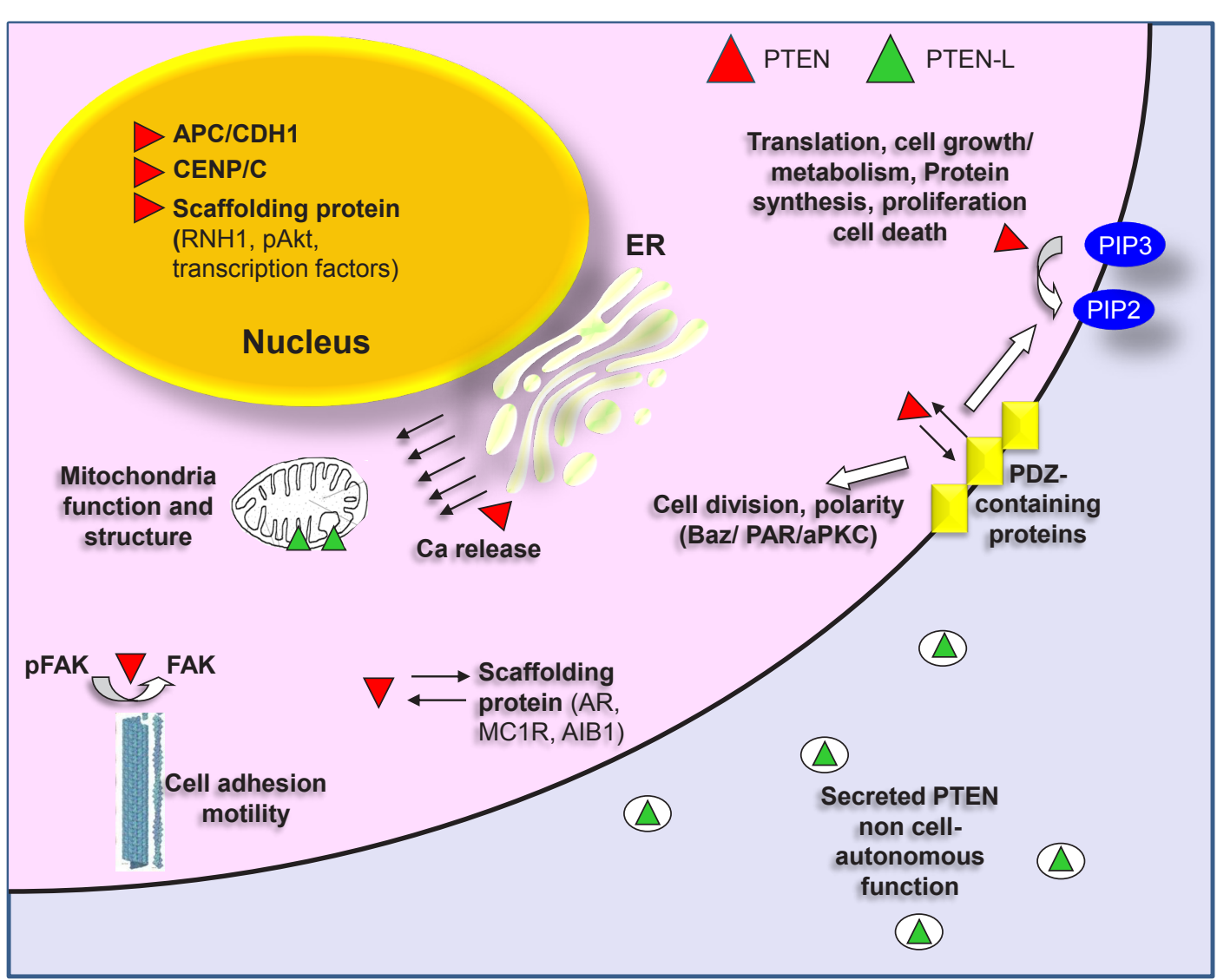

FIGURE 3 | PTEN localization and interactions with representative partners. Canonical PTEN (red) can be found in the cytoplasm or in cytoplasmic organelles (ER, mitochondria) and in the nucleus. The primary cellular substrate of PTEN is the second messenger phosphatidylinositol $(3,4,5)$-triphosphate (PIP3), which hydrolyzes giving phosphatidylinositol $(4,5)$-biphosphate (PIP2), thus regulating the PI3K pathway. PTEN needs to be recruited on the membrane to perform this function. The association with the membrane is regulated, among others, by interaction with PDZ-domain proteins (MAGl1/2/3). PDZ interaction between PTEN and Bazooka (a PDZ-domain containing protein) is also important for the formation of the PAR/ aPKC complex, which is required for the separation of apical and basolateral plasma membrane domains, for the asymmetric localization of cell fate determinants and for the proper orientation of the mitotic spindle. In the cytoplasm, PTEN also dephosphorylates FAK thus inhibiting cell adhesion. Finally, cytoplasmic PTEN also functions as a scaffolding protein. It associates with androgen receptor (AR), with melanocortin-1 receptor (MC1R) as well as with Amplified in breast cancer 1 (AIB1), a transcriptional coactivator. In all cases PTEN regulates the stability of these proteins by promoting their degradation. In the nucleus, PTEN also functions as a scaffolding protein. It interacts with transcription factors regulating their activity [p53, SMAD3, MTF-1 (metal-responsive transcription factor 1)]. It correlates with miRNA processing by interacting with $\mathrm{RNH} 1$ and interfering with the formation of Drosha complex and it promotes degradation of nuclear located proteins as in the case of PAKT. Nuclear PTEN interacts also with CENP/C promoting chromosomal integrity and positively regulates expression of Rad51, which reduces the incidence of spontaneous double-strand breaks (DSBs). Additionally, PTEN is required in the nucleus for the formation of the $\mathrm{APC} / \mathrm{CDH} 1$ complex, which is a regulator of cellular senescence and cell cycle. Canonical PTEN located in the $\mathrm{ER}$ is associated with $\mathrm{Ca}^{2+}$ release and regulation of apoptosis through interaction with the inositol 1,4,5-trisphosphate receptors (IP3Rs). A translational variant of PTEN (PTEN-L, green) is secreted and associated with the mitochondria. PTEN-L exerts its phosphatase activity outside the cell boundaries, whereas in mitochondria it is related to mitochondria structure and energy production. were found to associate with PTEN. In the case of S1PR, PTEN seems to be an intermediate in the signaling pathway regulating cell migration. Apparently, the receptor modulates the phosphorylation of PTEN through the activity of RhoA (166). MC1R is one of the key proteins involved in regulating mammalian skin and hair color. It is mainly expressed in melanocytes and was found to be involved in melanoma development (169). A series of mutations that have been identified in the MC1R gene disable the receptor from binding to PTEN thus permitting PTEN degradation by the WWP2 E3 ligase (167). PTEN also interacts with AR but in this case, the phosphatase prevents the receptor from being translocated to the nucleus and promotes its degradation in the cytoplasm (168).

\section{Metabolism}

Phosphatase and tensin homolog on chromosome 10 interacts with cytosolic $\alpha$-mannosidase $2 \mathrm{C} 1$ (MAN2C1), which is a catabolic enzyme for the breakdown of free oligosaccharides. Interaction of the enzyme with the PTEN seems to inhibit its phosphatase activity in prostate cancer cells (170).

Yeast two hybrid assays also revealed another interesting binding partner for PTEN involved in lipid metabolism, that 
is fatty acid binding protein 4 (FABP4) (171). FABP4 is mainly expressed in adipocyte tissue. These kinds of interactions point out additional roles for PTEN apart from cancer.

\section{Cytoskeletal Proteins}

Phosphatase and tensin homolog on chromosome 10 was found to interact directly with myosin and this interaction seems to be under the control of GSK2/GSK3-kinases. Abolishment of this interaction led to an increase in the neuronal soma size, which is the same phenotype acquired when PTEN function is lost (172).

\section{Kinases}

The interaction of PTEN with CK2, S6K, GSK3, as well as with PIK, RAK, and ROCK is described above.

Given that PTEN catalyzes the dephosphorylation of $\mathrm{PI}(3,4,5) \mathrm{P}_{3}$, which is required for Akt phosphorylation, it is anticipated that a role of PTEN would be to protect Akt from de novo phosphorylation. Surprisingly, PTEN has been shown to function as a scaffolding protein in the nuclei of the cells where it interacts with nuclear phosphorylated Akt leading to its depletion from the nucleus, most likely through proteasomal degradation (173).

An additional interaction of PTEN has been revealed in Drosophila melanogaster (174). The Ser/Thr kinase aPKC and the PDZ-domain protein Bazooka form a complex (PAR/aPKC complex), which is required for the separation of apical and basolateral plasma membrane domains, for the asymmetric localization of cell fate determinants and for the proper orientation of the mitotic spindle. PTEN was found to associate and co-localize with Baz and further data revealed that it exerts its function through the actin cytoskeleton (174).

Phosphatase and tensin homolog on chromosome 10 can also directly interact with and reduce adhesion-mediated Tyrphosphorylation of FAK (175). A key event during cell adhesion is the autophosphorylation of FAK at Tyr397, which is activated upon integrin-clustering. The Tyr397 autophosphorylation site is important for the interaction between FAK and PTEN, and this site has been shown to be dephosphorylated by PTEN. FAK dephosphorylation by PTEN appears to be dependent on cell attachment to specific ECM components (collagenI/IV). The involvement of PTEN in cell adhesion, motility, and invasion could be related to its role as a tumor suppressor gene product in various cell types (176).

LKB1 encodes a serine/threonine kinase generally inactivated in patients with Peutz-Jeghers syndrome (PJS). PTEN was identified as an LKB1-interacting protein. Several LKB1 point mutations associated with PJS disrupt the interaction of LKB1with PTEN suggesting that the loss of this interaction might contribute to PJS. In vitro data suggest that PTEN is a substrate of the kinase LKB1, whereas PTEN and LKB1 interaction leads to a cytoplasmic relocalization of LKB1 (177).

\section{Membrane-Associated Proteins}

Phosphatase and tensin homolog on chromosome 10 usually associates with membrane through PDZ-domain interaction. PDZ domains that bind to PTEN include the PDZ-2 domain from the scaffolding proteins MAGI-1/2/3 (133, 178, 179), the PDZ-2 domain from the human homolog of the Drosophila Dlg, hDlg/SAP97 (180), and the unique PDZ domain from the Ser/Thr kinase MAST205 (181). PTEN also binds to the PDZ domains from the MAST205-related protein kinases, SAST and MAST3 (182). PDZ-domain binding is suggested to have a regulatory role on PTEN function by controlling its stability and phosphorylation status.

Co-immunoprecipitation experiments also demonstrated that PTEN among other phosphatases form molecular complexes with caveolin-1 in vivo (183). PTEN can be recruited in caveolin rich membrane fractions where it exerts its functional role.

\section{Transcription Factors}

Phosphatase and tensin homolog on chromosome 10 is known to play a role in the regulation of numerous transcription factors. Metal-responsive transcription factor 1 (MTF-1) is a mammalian protein, which is essential for embryonic development and it modulates the expression of genes involved in zinc homeostasis and oxidative stress response. PTEN interacts via its phosphatase/ C2 domain with MTF-1 and enhances its activity. This regulation is independent of the nuclear translocation, protein stability, or DNA-binding activity of MTF-1 but is promoted by the addition of zinc ions (184).

Phosphatase and tensin homolog on chromosome 10 is the second most mutated tumor-suppressor gene other than p53. Interestingly, PTEN and $\mathrm{p} 53$ physically associate. This interaction leads to a significant increase in p53 stability and regulates the transcriptional activity of p53 by modulating its DNA-binding activity (185).

Amplified in breast cancer 1 (AIB1) is a transcriptional coactivator that regulates the transcriptional activities of nuclear receptors and other transcription factors. PTEN interacts with AIB1 and affects its transcriptional activity by enhancing its ubiquitinmediated degradation. More specifically, PTEN interacts with Fbw7alpha, an E3 ubiquitin ligase, acting as a bridge between AIB1 and Fbw7alpha. This leads to enhanced degradation of AIB1, which eventually accounts for its decreased transcriptional activity (186).

Last but not least, PTEN was found to interact with SMAD3 transcription factor acting downstream of TGF-beta transforming growth factor. TGF-beta promotes tumor progression through induction of tumor invasion, neoangiogenesis, and immunosuppression (187). Published data suggest that PTEN interacts with SMAD3 suppressing its transcriptional activity (188). It could be that loss of PTEN expression in advanced stages of human cancers may contribute to a role for TGF-beta as a tumor enhancer through the SMAD3 signaling cascade (188).

\section{Nuclear Located Proteins}

The PcG BMI1 gene maintains the proliferation potential and self-renewal of hematopoietic and neural stem cells and is considered a significant oncogene. PTEN binds to BMI1 exclusively in the nucleus and reduces its function. This interaction does not require the phosphatase activity of PTEN (189).

Phosphatase and tensin homolog on chromosome 10 was also shown to negatively regulate the expression of oncogenic 
miR-21 at the post-transcriptional level. A microRNA molecule is synthesized as a long RNA primary transcript known as a pri$m i R N A$, which is cleaved by Drosha in the nucleus to produce a characteristic stem-loop structure of about 70 bp long, known as a pre-miRNA. RNH1 is an RNA-interacting protein, which was shown to interact with Drosha. This interaction was necessary and sufficient for miR-21 processing and it was shown to be blocked due to PTEN-RNH1 interaction (190).

Besides its well characterized role as a lipid phosphatase, PTEN is considered a guardian of genomic stability. PTEN maintains chromosomal integrity by physical interaction with CENP-C, which is a constitutive protein component of the centromere and is essential for centromere formation. PTEN was also found to be localized in the centromere, probably due to its association with CENP-C, and loss of its expression led to extensive centromere breakage. The PTEN-centromere interaction is independent of its phosphatase activity (191).

Phosphatase and tensin homolog on chromosome 10 was also shown to interact with the anaphase promoting complex/ cyclosome (APC/CDH1), which is a ubiquitin E3-ligase complex located in the nucleus and controls the degradation of cell-cycle regulators, such as cyclin, securin, Aurora, etc (192). This interaction is necessary for the formation of the APC/CDH1 complex and it seems to be independent of the phosphatase activity of PTEN (193).

\section{PTEN Regulators}

Phosphatase and tensin homolog on chromosome 10 function was shown to be regulated by two proteins; shank-interacting protein-like 1 (SIPL1), which is a member of the NF- $\kappa$ B-activating linear ubiquitin chain assembly complex and protein interacting with carboxyl terminus 1 (PICT-1), which is localized to the nucleus and/or nucleolus. SIPL1 interacts with PTEN through its ubiquitin-like domain (UBL), inhibiting its phosphatase activity (194), whereas PICT-1 binds to the C terminus of PTEN and promotes its phosphorylation and stability (195).

\section{PTEN Localization}

As discussed above, PTEN was shown to localize between the cytosol and the plasma membrane and in the nucleus where it is proposed to play a role in the stability of the genome. More data support that PTEN can also be found extracellularly as well as in cytoplasmic organelles [ER, mitochondria-associated membranes (MAM), and mitochondria] (196) (Figure 3).

\section{Plasma Membrane}

Despite the fact that PTEN is required to bind to the membrane to exert its phosphatase activity, it seems that this association is not a steady state situation. Indeed, the N-terminal PIP2-binding motif was shown to drive PTEN on the membrane when PIP2 membrane fraction is enriched $(197,198)$. Furthermore, the C2 domain of PTEN was found to contain basic residues which are essential for membrane binding (115). However, the association of PTEN to the plasma membrane is regulated by a series of factors. Interaction of the phosphatase with membrane-associated proteins, mainly PDZ-domain proteins, such as MAGI-1, -2, -3
(132, 133, 179), can increase the local PTEN concentration on the membrane (this interaction is discussed above). Apart from that, post-translational modifications also regulate the membrane association of the protein. Such modifications include phosphorylation of the C-tail of PTEN that changes the PTEN conformation and inhibits the membrane binding $(126-128,130,199)$ as well as SUMO 1 modification, which was shown to enhance its membrane association (164).

\section{Nucleus and Nucleolus}

The function of PTEN does not rely solely on its lipid phosphatase activity. $\mathrm{PI}(3,4,5) \mathrm{P}_{3}$ was shown to localize also in the nucleus and although its levels were affected by PI3K inhibitors, they remained unaffected after the expression of PTEN implying that nuclear PTEN serves another function in the cell (200). Indeed, localization of PTEN in the nucleus was shown to correlate significantly with the suppressive role of the protein during tumor development independently of its phosphatase activity. To begin with, nuclear PTEN is a protector of genomic stability. Interaction of PTEN with CENP/C promotes chromosomal integrity and positively regulates the expression of Rad51, which reduces the incidence of spontaneous double-strand breaks (DSBs) (191). Additionally, PTEN is required in the nucleus for the formation of the APC/CDH1 complex, which is a regulator of cellular senescence and cell cycle and thus a significant tumor suppressor (193). PTEN also localizes to the nucleolus, and nucleolar PTEN plays an important role in regulating nucleolar homeostasis and maintaining nucleolar morphology (201).

Transport of PTEN in the nucleus was shown to confront to the classic mechanisms and signals for nuclear import. More specifically, the first 32 amino acids of PTEN, which contain a functional PIP2-binding domain that is involved in targeting of PTEN to the plasma membrane, were also shown to contain a functional nuclear localization signal $(136,202)$. Additionally, import of the protein in the nucleus is dependent on the activity of importins and of Ran-GTPase (136).

Several groups have reported the association of vaults with the nucleus and particularly the nucleoli, the nuclear membrane, and/or the nuclear pore complex and MVPs have been hypothesized as carrier molecules for nuclear-cytoplasmic transport (203). Recently, PTEN was found to associate with MVP (204), whereas more data reveal that this interaction leads to PTEN nuclear import (205). Finally, other researchers suggest that entry of PTEN in the nucleus occurs via diffusion and is not an active process (206). In any case, PTEN nuclear localization is a finely tuned process regulated by ubiquitination (153) as well as by sumoylation of the protein (165).

\section{Cytoplasmic Organelles}

An N-terminally extended form of PTEN, which contains 173 additional amino-terminal amino acids (PTEN long; PTEN-L) was found to be expressed and transported in the mitochondria. Translation of PTEN-L is initiated from a CUG codon upstream of AUG and in-frame with the coding region of canonical PTEN. PTEN-L associates with canonical PTEN and the complex serves a role in mitochondrial bioenergetics. Furthermore, depletion of PTEN-L was shown to impair the mitochondrial structure (207). 
Apoptosis is a phenotype of cell death and is a process where both mitochondria and endoplasmic reticulum (ER) seem to play a crucial role. A mitochondrial location and accumulation of PTEN after challenging with staurosporine, an apoptosis inducer, were demonstrated after isolation of mitochondrial fractions from primary rat hippocampal cultures. Furthermore, suppression of PTEN expression significantly reduced the increased ROS level detected after the onset of apoptosis and protected hippocampal neurons from STS-induced apoptotic damage (208).

Phosphatase and tensin homolog on chromosome 10 was also shown to localize in the ER and in MAM. PTEN localization at the ER is further increased during calcium $\left(\mathrm{Ca}^{2+}\right)$ dependent apoptosis induction (209). The regulation of $\mathrm{Ca}^{2+}$ concentration is fundamental process for cell metabolism, proliferation, differentiation, and cell death. Elevation in intracellular $\mathrm{Ca}^{2+}$ concentration comes either from $\mathrm{Ca}^{2+}$ influx from the extracellular space or from $\mathrm{Ca}^{2+}$ release from the ER and leads to $\mathrm{Ca}^{2+}$ overload in the mitochondria. This induces the swelling of mitochondria, with perturbation or rupture of the outer membrane, and in turn the release of mitochondrial apoptotic factors into the cytosol (209-211). PTEN silencing impairs $\mathrm{ER} \mathrm{Ca}^{2+}$ release, thus reducing the cytosolic and mitochondrial $\mathrm{Ca}^{2+}$ concentration leading to decreased cellular sensitivity to $\mathrm{Ca}^{2+}$-mediated apoptotic stimulation (209). It is proposed that PTEN interacts with and dephosphorylates the inositol 1,4,5-trisphosphate receptors (IP3Rs), which when phosphorylated discharge $\mathrm{Ca}^{2+}$ from ER. In this concept, ER-localized PTEN regulates $\mathrm{Ca}^{2+}$ release from the ER in a protein phosphatase-dependent manner (209).

\section{Extracellular PTEN}

Surprisingly, PTEN-L identified in mitochondria was also found to be secreted. More specifically, PTEN-L was found to be localized in exosomes, microvesicles of endosomal origin that are secreted (212). PTEN secretion in exosomes required Nedd4-1

\section{References}

1. Govender D, Chetty R. Gene of the month: PTEN. J Clin Pathol (2012) 65:601-3. doi:10.1136/jclinpath-2012-200711

2. Li DM, Sun H. TEP1, encoded by a candidate tumor suppressor locus, is a novel protein tyrosine phosphatase regulated by transforming growth factor beta. Cancer Res (1997) 57:2124-9.

3. Li J, Yen C, Liaw D, Podsypanina K, Bose S, Wang SI, et al. PTEN, a putative protein tyrosine phosphatase gene mutated in human brain, breast, and prostate cancer. Science (1997) 275:1943-7. doi:10.1126/science.275.5308.1943

4. Steck PA, Pershouse MA, Jasser SA, Yung WK, Lin H, Ligon AH, et al. Identification of a candidate tumour suppressor gene, MMAC1, at chromosome 10q23.3 that is mutated in multiple advanced cancers. Nat Genet (1997) 15:356-62. doi:10.1038/ng0497-356

5. Di Cristofano A, Pandolfi PP. The multiple roles of PTEN in tumor suppression. Cell (2000) 100:387-90. doi:10.1016/S0092-8674(00)80674-1

6. Xu WT, Yang Z, Lu NH. Roles of PTEN (phosphatase and tensin homolog) in gastric cancer development and progression. Asian Pac J Cancer Prev (2014) 15:17-24. doi:10.7314/APJCP.2014.15.1.17

7. Myers MP, Tonks NK. PTEN: sometimes taking it off can be better than putting it on. Am J Hum Genet (1997) 61:1234-8. doi:10.1086/301659

8. Ye B, Jiang LL, Xu HT, Zhou DW, Li ZS. Expression of PI3K/AKT pathway in gastric cancer and its blockade suppresses tumor growth and metastasis. Int J Immunopathol Pharmacol (2012) 25:627-36. and Nedd4-2 members of the Nedd4 family of E3 ubiquitin ligases as well as Ndfip1, an adaptor protein for the ubiquitin ligases. In addition, lysine 13 within PTEN, which is required for its ubiquitination by Nedd4-1, was required for exosomal transport of PTEN (213). Secreted PTEN enters neighboring cells (212, 213). In fact, the internalization signal for the uptake of PTEN-L into acceptor cells is included in the 173 additional amino acids it contains (212). More importantly, due to the property of PTEN to be secreted, its function is no longer considered to be cellautonomous. Indeed, uptake of PTEN was shown to antagonize PI3K signaling, to reduce cell proliferation and induce tumor cell death in vitro and in vivo $(130,214)$.

\section{Conclusion}

The progress that has been made over the last years in the knowledge of PTEN regulation is remarkable. A wealth of studies has provided novel and unexpected insights into mechanisms of PTEN regulation adding a "positive" complexity in the field. The existence of multiple mechanisms that regulate PTEN expression and activity led to a better understanding of its role in diseases that is expected to contribute to an improvement of the current therapeutic strategies and identification of novel therapeutic approaches. The challenge now is these insights to be placed within a structure to understand how different regulation mechanisms can be targeted by putative new agents in certain diseases.

\section{Acknowledgments}

Authors' work is supported by the programme NSRF 2007-2013, "Education and Lifelong Learning" (Action ARISTEIA II, Project No. 4078) of the Ministry of Education and Religious Affairs, Greece, co-financed by Greece and the European Union, and by the Research Committee of the University of Crete (KA 4059).

9. Vanhaesebroeck B, Leevers SJ, Panayotou G, Waterfield MD. Phosphoinositide 3-kinases: a conserved family of signal transducers. Trends Biochem Sci (1997) 22:267-72. doi:10.1016/S0968-0004(97)01061-X

10. Vanhaesebroeck B, Guillermet-Guibert J, Graupera M, Bilanges B. The emerging mechanisms of isoform-specific PI3K signalling. Nat Rev Mol Cell Biol (2010) 11:329-41. doi:10.1038/nrm2882

11. Engelman JA, Luo J, Cantley LC. The evolution of phosphatidylinositol 3-kinases as regulators of growth and metabolism. Nat Rev Genet (2006) 7:606-19. doi:10.1038/nrg1879

12. Liu P, Cheng H, Roberts TM, Zhao JJ. Targeting the phosphoinositide 3-kinase pathway in cancer. Nat Rev Drug Discov (2009) 8:627-44. doi:10.1038/ nrd2926

13. Stephens LR, Eguinoa A, Erdjument-Bromage H, Lui M, Cooke F, Coadwell J, et al. The G beta gamma sensitivity of a PI3K is dependent upon a tightly associated adaptor, p101. Cell (1997) 89:105-14. doi:10.1016/S0092-8674 (00)80187-7

14. Krugmann S, Hawkins PT, Pryer N, Braselmann S. Characterizing the interactions between the two subunits of the p101/p110gamma phosphoinositide 3-kinase and their role in the activation of this enzyme by G beta gamma subunits. J Biol Chem (1999) 274:17152-8. doi:10.1074/jbc.274.24.17152

15. Suire S, Coadwell J, Ferguson GJ, Davidson K, Hawkins P, Stephens L. p84, a new gbetagamma-activated regulatory subunit of the type IB phosphoinositide 3-kinase p110gamma. Curr Biol (2005) 15:566-70. doi:10.1016/j. cub. 2005.02 .020 
16. Voigt P, Dorner MB, Schaefer M. Characterization of p87PIKAP, a novel regulatory subunit of phosphoinositide 3-kinase gamma that is highly expressed in heart and interacts with PDE3B. J Biol Chem (2006) 281:9977-86. doi:10.1074/jbc.M512502200

17. Davies MA. Regulation, role, and targeting of Akt in cancer. J Clin Oncol (2011) 29:4715-7. doi:10.1200/JCO.2011.37.4751

18. Vanhaesebroeck B, Leevers SJ, Ahmadi K, Timms J, Katso R, Driscoll PC, et al. Synthesis and function of 3-phosphorylated inositol lipids. Annu Rev Biochem (2001) 70:535-602. doi:10.1146/annurev.biochem.70.1.535

19. Alessi DR, Deak M, Casamayor A, Caudwell FB, Morrice N, Norman DG, et al. 3-Phosphoinositide-dependent protein kinase-1 (PDK1): structural and functional homology with the Drosophila DSTPK61 kinase. Curr Biol (1997) 7:776-89. doi:10.1016/S0960-9822(06)00336-8

20. Maehama T, Dixon JE. The tumor suppressor, PTEN/MMAC1, dephosphorylates the lipid second messenger, phosphatidylinositol 3,4,5-trisphosphate. J Biol Chem (1998) 273:13375-8. doi:10.1074/jbc.273.22.13375

21. Leevers SJ, Vanhaesebroeck B, Waterfield MD. Signalling through phosphoinositide 3-kinases: the lipids take centre stage. Curr Opin Cell Biol (1999) 11:219-25. doi:10.1016/S0955-0674(99)80029-5

22. Leslie NR, Downes CP. PTEN function: how normal cells control it and tumour cells lose it. Biochem J (2004) 382:1-11. doi:10.1042/BJ20040825

23. Parsons R. Human cancer, PTEN and the PI-3 kinase pathway. Semin Cell Dev Biol (2004) 15:171-6. doi:10.1016/j.semcdb.2003.12.021

24. Sansal I, Sellers WR. The biology and clinical relevance of the PTEN tumor suppressor pathway. J Clin Oncol (2004) 22:2954-63. doi:10.1200/ JCO.2004.02.141

25. Cully M, You H, Levine AJ, Mak TW. Beyond PTEN mutations: the PI3K pathway as an integrator of multiple inputs during tumorigenesis. Nat Rev Cancer (2006) 6:184-92. doi:10.1038/nrc1819

26. Li DM, Sun H. PTEN/MMAC1/TEP1 suppresses the tumorigenicity and induces G1 cell cycle arrest in human glioblastoma cells. Proc Natl Acad Sci U S A (1998) 95:15406-11. doi:10.1073/pnas.95.26.15406

27. Norimatsu Y, Moriya T, Kobayashi TK, Sakurai T, Shimizu K, Tsukayama C, et al. Immunohistochemical expression of PTEN and beta-catenin for endometrial intraepithelial neoplasia in Japanese women. Ann Diagn Pathol (2007) 11:103-8. doi:10.1016/j.anndiagpath.2006.06.009

28. Mackay HJ, Gallinger S, Tsao MS, Mclachlin CM, Tu D, Keiser K, et al. Prognostic value of microsatellite instability (MSI) and PTEN expression in women with endometrial cancer: results from studies of the NCIC clinical trials group (NCIC CTG). Eur J Cancer (2010) 46:1365-73. doi:10.1016/j. ejca.2010.02.031

29. You Y, Geng X, Zhao P, Fu Z, Wang C, Chao S, et al. Evaluation of combination gene therapy with PTEN and antisense hTERT for malignant glioma in vitro and xenografts. Cell Mol Life Sci (2007) 64:621-31. doi:10.1007/ s00018-007-6424-4

30. Xu J, Li Z, Wang J, Chen H, Fang JY. Combined PTEN mutation and protein expression associate with overall and disease-free survival of glioblastoma patients. Transl Oncol (2014) 7(196-205):e191. doi:10.1016/j. tranon.2014.02.004

31. Romano C, Schepis C. PTEN gene: a model for genetic diseases in dermatology. ScientificWorldJournal (2012) 2012:252457. doi:10.1100/2012/252457

32. Baig RM, Mahjabeen I, Sabir M, Masood N, Hafeez S, Malik FA, et al. Genetic changes in the PTEN gene and their association with breast cancer in Pakistan. Asian Pac J Cancer Prev (2011) 12:2773-8.

33. Davis NM, Sokolosky M, Stadelman K, Abrams SL, Libra M, Candido S, et al. Deregulation of the EGFR/PI3K/PTEN/Akt/mTORC1 pathway in breast cancer: possibilities for therapeutic intervention. Oncotarget (2014) 5:4603-50.

34. Patel R, Gao M, Ahmad I, Fleming J, Singh LB, Rai TS, et al. Sprouty2, PTEN, and PP2A interact to regulate prostate cancer progression. J Clin Invest (2013) 123:1157-75. doi:10.1172/JCI63672

35. Birnbaum Y, Nanhwan MK, Ling S, Perez-Polo JR, Ye Y, Bajaj M. PTEN upregulation may explain the development of insulin resistance and type 2 diabetes with high dose statins. Cardiovasc Drugs Ther (2014) 28:447-57. doi:10.1007/s10557-014-6546-5

36. Worby CA, Dixon JE. Pten. Annu Rev Biochem (2014) 83:641-69. doi:10.1146/ annurev-biochem-082411-113907

37. Shi Y, Paluch BE, Wang X, Jiang X. PTEN at a glance. J Cell Sci (2012) 125:4687-92. doi:10.1242/jcs.093765
38. Song MS, Salmena L, Pandolfi PP. The functions and regulation of the PTEN tumour suppressor. Nat Rev Mol Cell Biol (2012) 13:283-96. doi:10.1038/ nrm3330

39. Patel L, Pass I, Coxon P, Downes CP, Smith SA, Macphee CH. Tumor suppressor and anti-inflammatory actions of PPARgamma agonists are mediated via upregulation of PTEN. Curr Biol (2001) 11:764-8. doi:10.1016/ S0960-9822(01)00225-1

40. Stambolic V, Macpherson D, Sas D, Lin Y, Snow B, Jang Y, et al. Regulation of PTEN transcription by p53. Mol Cell (2001) 8:317-25. doi:10.1016/ S1097-2765(01)00323-9

41. Virolle T, Adamson ED, Baron V, Birle D, Mercola D, Mustelin T, et al. The Egr-1 transcription factor directly activates PTEN during irradiation-induced signalling. Nat Cell Biol (2001) 3:1124-8. doi:10.1038/ncb1201-1124

42. Edwin F, Singh R, Endersby R, Baker SJ, Patel TB. The tumor suppressor PTEN is necessary for human sprouty 2-mediated inhibition of cell proliferation. J Biol Chem (2006) 281:4816-22. doi:10.1074/jbc.M508300200

43. Hettinger K, Vikhanskaya F, Poh MK, Lee MK, De Belle I, Zhang JT, et al. c-Jun promotes cellular survival by suppression of PTEN. Cell Death Differ (2007) 14:218-29. doi:10.1038/sj.cdd.4401946

44. Vasudevan KM, Gurumurthy S, Rangnekar VM. Suppression of PTEN expression by NF-kappa B prevents apoptosis. Mol Cell Biol (2004) 24:100721. doi:10.1128/MCB.24.3.1007-1021.2004

45. Gericke A, Munson M, Ross AH. Regulation of the PTEN phosphatase. Gene (2006) 374:1-9. doi:10.1016/j.gene.2006.02.024

46. Song LB, Li J, Liao WT, Feng Y, Yu CP, Hu LJ, et al. The polycomb group protein Bmi-1 represses the tumor suppressor PTEN and induces epithelial-mesenchymal transition in human nasopharyngeal epithelial cells. J Clin Invest (2009) 119:3626-36. doi:10.1172/JCI39374

47. Lau MT, Klausen C, Leung PC. E-cadherin inhibits tumor cell growth by suppressing PI3K/Akt signaling via beta-catenin-Egr1-mediated PTEN expression. Oncogene (2011) 30:2753-66. doi:10.1038/onc.2011.6

48. Meng X, Wang Y, Zheng X, Liu C, Su B, Nie H, et al. shRNA-mediated knockdown of Bmi-1 inhibit lung adenocarcinoma cell migration and metastasis. Lung Cancer (2012) 77:24-30. doi:10.1016/j.lungcan.2012.02.015

49. Kang YH, Lee HS, Kim WH. Promoter methylation and silencing of PTEN in gastric carcinoma. Lab Invest (2002) 82:285-91. doi:10.1038/ labinvest. 3780422

50. Garcia JM, Silva J, Pena C, Garcia V, Rodriguez R, Cruz MA, et al. Promoter methylation of the PTEN gene is a common molecular change in breast cancer. Genes Chromosomes Cancer (2004) 41:117-24. doi:10.1002/gcc.20062

51. Goel A, Arnold CN, Niedzwiecki D, Carethers JM, Dowell JM, Wasserman L, et al. Frequent inactivation of PTEN by promoter hypermethylation in microsatellite instability-high sporadic colorectal cancers. Cancer Res (2004) 64:3014-21. doi:10.1158/0008-5472.CAN-2401-2

52. Mirmohammadsadegh A, Marini A, Nambiar S, Hassan M, Tannapfel A, Ruzicka T, et al. Epigenetic silencing of the PTEN gene in melanoma. Cancer Res (2006) 66:6546-52. doi:10.1158/0008-5472.CAN-06-0384

53. Zysman MA, Chapman WB, Bapat B. Considerations when analyzing the methylation status of PTEN tumor suppressor gene. Am J Pathol (2002) 160:795-800. doi:10.1016/S0002-9440(10)64902-4

54. Hesson LB, Packham D, Pontzer E, Funchain P, Eng C, Ward RL. A reinvestigation of somatic hypermethylation at the PTEN CPG island in cancer cell lines. Biol Proced Online (2012) 14:5. doi:10.1186/1480-9222-14-5

55. Hesson LB, Ward RL. Discrimination of pseudogene and parental gene DNA methylation using allelic bisulfite sequencing. Methods Mol Biol (2014) 1167:265-74. doi:10.1007/978-1-4939-0835-6_18

56. Palomero T, Sulis ML, Cortina M, Real PJ, Barnes K, Ciofani M, et al. Mutational loss of PTEN induces resistance to NOTCH1 inhibition in T-cell leukemia. Nat Med (2007) 13:1203-10. doi:10.1038/nm1636

57. Chappell WH, Green TD, Spengeman JD, Mccubrey JA, Akula SM, Bertrand FE. Increased protein expression of the PTEN tumor suppressor in the presence of constitutively active Notch-1. Cell Cycle (2005) 4:1389-95. doi:10.4161/cc.4.10.2028

58. Whelan JT, Forbes SL, Bertrand FE. CBF-1 (RBP-J kappa) binds to the PTEN promoter and regulates PTEN gene expression. Cell Cycle (2007) 6:80-4. doi:10.4161/cc.6.1.3648

59. Bartel DP. MicroRNAs: genomics, biogenesis, mechanism, and function. Cell (2004) 116:281-97. doi:10.1016/S0092-8674(04)00045-5 
60. Bartel DP, Chen CZ. Micromanagers of gene expression: the potentially widespread influence of metazoan microRNAs. Nat Rev Genet (2004) 5:396-400. doi: $10.1038 / \operatorname{nrg} 1328$

61. van den Berg A, Mols J, Han J. RISC-target interaction: cleavage and translational suppression. Biochim Biophys Acta (2008) 1779:668-77. doi:10.1016/j. bbagrm.2008.07.005

62. Ambros V. The functions of animal microRNAs. Nature (2004) 431:350-5. doi:10.1038/nature02871

63. Miska EA. How microRNAs control cell division, differentiation and death. Curr Opin Genet Dev (2005) 15:563-8. doi:10.1016/j.gde.2005.08.005

64. Wilmott JS, Zhang XD, Hersey P, Scolyer RA. The emerging important role of microRNAs in the pathogenesis, diagnosis and treatment of human cancers. Pathology (2011) 43:657-71. doi:10.1097/PAT.0b013e32834a7358

65. Nair VS, Maeda LS, Ioannidis JP. Clinical outcome prediction by microRNAs in human cancer: a systematic review. J Natl Cancer Inst (2012) 104:528-40. doi:10.1093/jnci/djs027

66. Hunt S, Jones AV, Hinsley EE, Whawell SA, Lambert DW. MicroRNA-124 suppresses oral squamous cell carcinoma motility by targeting ITGB1. FEBS Lett (2011) 585:187-92. doi:10.1016/j.febslet.2010.11.038

67. Wu L, Cai C, Wang X, Liu M, LiX, Tang H. MicroRNA-142-3p, a new regulator of RAC1, suppresses the migration and invasion of hepatocellular carcinoma cells. FEBS Lett (2011) 585:1322-30. doi:10.1016/j.febslet.2011.03.067

68. Wang Z, Zhang X, Yang Z, Du H, Wu Z, Gong J, et al. MiR-145 regulates PAK4 via the MAPK pathway and exhibits an antitumor effect in human colon cells. Biochem Biophys Res Commun (2012) 427:444-9. doi:10.1016/j.bbrc.2012.06.123

69. Lin SC, Liu CJ, Lin JA, Chiang WF, Hung PS, Chang KW. miR-24 up-regulation in oral carcinoma: positive association from clinical and in vitro analysis. Oral Oncol (2010) 46:204-8. doi:10.1016/j.oraloncology.2009.12.005

70. Liu C, Yu J, Yu S, Lavker RM, Cai L, Liu W, et al. MicroRNA-21 acts as an oncomir through multiple targets in human hepatocellular carcinoma. J Hepatol (2010) 53:98-107. doi:10.1016/j.jhep.2010.02.021

71. Yang L, Li Q, Wang Q, Jiang Z, Zhang L. Silencing of miRNA-218 promotes migration and invasion of breast cancer via Slit2-Robo1 pathway. Biomed Pharmacother (2012) 66:535-40. doi:10.1016/j.biopha.2012.04.006

72. He L. Posttranscriptional regulation of PTEN dosage by noncoding RNAs. Sci Signal (2010) 3:e39. doi:10.1126/scisignal.3146pe39

73. Meng F, Henson R, Wehbe-Janek H, Ghoshal K, Jacob ST, Patel T. MicroRNA-21 regulates expression of the PTEN tumor suppressor gene in human hepatocellular cancer. Gastroenterology (2007) 133:647-58. doi:10.1053/j.gastro.2007.05.022

74. Wang B, Majumder S, Nuovo G, Kutay H, Volinia S, Patel T, et al. Role of microRNA-155 at early stages of hepatocarcinogenesis induced by choline-deficient and amino acid-defined diet in C57BL/6 mice. Hepatology (2009) 50:1152-61. doi:10.1002/hep.23100

75. Poliseno L, Salmena L, Riccardi L, Fornari A, Song MS, Hobbs RM, et al. Identification of the miR-106b 25 microRNA cluster as a proto-oncogenic PTEN-targeting intron that cooperates with its host gene MCM7 in transformation. Sci Signal (2010) 3:ra29. doi:10.1126/scisignal.2000594

76. Jindra PT, Bagley J, Godwin JG, Iacomini J. Costimulation-dependent expression of microRNA-214 increases the ability of T cells to proliferate by targeting Pten. J Immunol (2010) 185:990-7. doi:10.4049/jimmunol.1000793

77. Xiao C, Srinivasan L, Calado DP, Patterson HC, Zhang B, Wang J, et al. Lymphoproliferative disease and autoimmunity in mice with increased miR-17-92 expression in lymphocytes. Nat Immunol (2008) 9:405-14. doi:10.1038/ni1575

78. Mu P, Han YC, Betel D, Yao E, Squatrito M, Ogrodowski P, et al. Genetic dissection of the miR-17 92 cluster of microRNAs in Myc-induced B-cell lymphomas. Genes Dev (2009) 23:2806-11. doi:10.1101/gad.1872909

79. Olive V, Bennett MJ, Walker JC, Ma C, Jiang I, Cordon-Cardo C, et al. miR-19 is a key oncogenic component of mir-17-92. Genes Dev (2009) 23:2839-49. doi:10.1101/gad.1861409

80. Liu ZL, Wang H, Liu J, Wang ZX. MicroRNA-21 (miR-21) expression promotes growth, metastasis, and chemo- or radioresistance in non-small cell lung cancer cells by targeting PTEN. Mol Cell Biochem (2013) 372:35-45. doi:10.1007/s11010-012-1443-3

81. Xiong Y, Zhang YY, Wu YY, Wang XD, Wan LH, Li L, et al. Correlation of over-expressions of miR-21 and Notch-1 in human colorectal cancer with clinical stages. Life Sci (2014) 106:19-24. doi:10.1016/j.lfs.2014.04.017
82. Lou Y, Yang X, Wang F, Cui Z, Huang Y. MicroRNA-21 promotes the cell proliferation, invasion and migration abilities in ovarian epithelial carcinomas through inhibiting the expression of PTEN protein. Int J Mol Med (2010) 26:819-27. doi:10.3892/ijmm_00000530

83. Dong G, Liang X, Wang D, Gao H, Wang L, Wang L, et al. High expression of miR-21 in triple-negative breast cancers was correlated with a poor prognosis and promoted tumor cell in vitro proliferation. Med Oncol (2014) 31:57. doi:10.1007/s12032-014-0057-x

84. Iliopoulos D, Jaeger SA, Hirsch HA, Bulyk ML, Struhl K. STAT3 activation of miR-21 and miR-181b-1 via PTEN and CYLD are part of the epigenetic switch linking inflammation to cancer. Mol Cell (2010) 39:493-506. doi:10.1016/j. molcel.2010.07.023

85. Yang H, Kong W, He L, Zhao JJ, O’Donnell JD, Wang J, et al. MicroRNA expression profiling in human ovarian cancer: miR-214 induces cell survival and cisplatin resistance by targeting PTEN. Cancer Res (2008) 68:425-33. doi:10.1158/0008-5472.CAN-07-2488

86. Penna E, Orso F, Taverna D. miR-214 as a key hub that controls cancer networks: small player, multiple functions. J Invest Dermatol (2015) 135:960-9. doi:10.1038/jid.2014.479

87. Fu X, Tian J, Zhang L, Chen Y, Hao Q. Involvement of microRNA-93, a new regulator of PTEN/Akt signaling pathway, in regulation of chemotherapeutic drug cisplatin chemosensitivity in ovarian cancer cells. FEBS Lett (2012) 586:1279-86. doi:10.1016/j.febslet.2012.03.006

88. Yang L, Li N, Wang H, Jia X, Wang X, Luo J. Altered microRNA expression in cisplatin-resistant ovarian cancer cells and upregulation of miR-130a associated with MDR1/P-glycoprotein-mediated drug resistance. Oncol Rep (2012) 28:592-600. doi:10.3892/or.2012.1823

89. Li NW, Wang HJ, Yang LY, Jia XB, Chen C, Wang X. [Regulatory effects and associated mechanisms of miR-130a molecules on cisplatin resistance in ovarian cancer A2780 cell lines]. Sichuan Da Xue Xue Bao Yi Xue Ban (2013) 44:865-70.

90. Xie Q, Yan Y, Huang Z, Zhong X, Huang L. MicroRNA-221 targeting PI3-K/ Akt signaling axis induces cell proliferation and BCNU resistance in human glioblastoma. Neuropathology (2014) 34:455-64. doi:10.1111/neup.12129

91. Huse JT, Brennan C, Hambardzumyan D, Wee B, Pena J, Rouhanifard SH, et al. The PTEN-regulating microRNA miR-26a is amplified in high-grade glioma and facilitates gliomagenesis in vivo. Genes Dev (2009) 23:1327-37. doi:10.1101/gad.1777409

92. Liu B, Wu X, Liu B, Wang C, Liu Y, Zhou Q, et al. MiR-26a enhances metastasis potential of lung cancer cells via AKT pathway by targeting PTEN. Biochim Biophys Acta (2012) 1822:1692-704. doi:10.1016/j.bbadis.2012.07.019

93. Lang Y, Xu S, Ma J, Wu J, Jin S, Cao S, et al. MicroRNA-429 induces tumorigenesis of human non-small cell lung cancer cells and targets multiple tumor suppressor genes. Biochem Biophys Res Commun (2014) 450:154-9. doi:10.1016/j.bbrc.2014.05.084

94. Wang C, Bian Z, Wei D, Zhang JG. miR-29b regulates migration of human breast cancer cells. Mol Cell Biochem (2011) 352:197-207. doi:10.1007/ s11010-011-0755-z

95. Shi W, Gerster K, Alajez NM, Tsang J, Waldron L, Pintilie M, et al. MicroRNA-301 mediates proliferation and invasion in human breast cancer. Cancer Res (2011) 71:2926-37. doi:10.1158/0008-5472.CAN-10-3369

96. Ma F, Zhang J, Zhong L, Wang L, Liu Y, Wang Y, et al. Upregulated microRNA-301a in breast cancer promotes tumor metastasis by targeting PTEN and activating Wnt/beta-catenin signaling. Gene (2014) 535:191-7. doi:10.1016/j. gene.2013.11.035

97. Wu Z, He B, He J, Mao X. Upregulation of miR-153 promotes cell proliferation via downregulation of the PTEN tumor suppressor gene in human prostate cancer. Prostate (2013) 73:596-604. doi:10.1002/pros.22600

98. Tian L, Fang YX, Xue JL, Chen JZ. Four microRNAs promote prostate cell proliferation with regulation of PTEN and its downstream signals in vitro. PLoS One (2013) 8:e75885. doi:10.1371/journal.pone.0075885

99. Ke TW, Wei PL, Yeh KT, Chen WT, Cheng YW. MiR-92a promotes cell metastasis of colorectal cancer through PTEN-mediated PI3K/AKT pathway. Ann Surg Oncol (2014). doi:10.1245/s10434-014-4305-2

100. Sun HB, Chen X, Ji H, Wu T, Lu HW, Zhang Y, et al. miR494 is an independent prognostic factor and promotes cell migration and invasion in colorectal cancer by directly targeting PTEN. Int J Oncol (2014) 45:2486-94. doi:10.3892/ ijo.2014.2665 
101. Geng L, Sun B, Gao B, Wang Z, Quan C, Wei F, et al. MicroRNA-103 promotes colorectal cancer by targeting tumor suppressor DICER and PTEN. Int J Mol Sci (2014) 15:8458-72. doi:10.3390/ijms15058458

102. Wu W, Yang J, Feng X, Wang H, Ye S, Yang P, et al. MicroRNA-32 (miR32) regulates phosphatase and tensin homologue (PTEN) expression and promotes growth, migration, and invasion in colorectal carcinoma cells. Mol Cancer (2013) 12:30. doi:10.1186/1476-4598-12-30

103. Yan SY, Chen MM, Li GM, Wang YQ, Fan JG. MiR-32 induces cell proliferation, migration, and invasion in hepatocellular carcinoma by targeting PTEN. Tumour Biol (2015). doi:10.1007/s13277-015-3124-9

104. Croce CM. Causes and consequences of microRNA dysregulation in cancer. Nat Rev Genet (2009) 10:704-14. doi:10.1038/nrg2634

105. Salmena L, Poliseno L, Tay Y, Kats L, Pandolfi PP. A ceRNA hypothesis: the Rosetta Stone of a hidden RNA language? Cell (2011) 146:353-8. doi:10.1016/j.cell.2011.07.014

106. Cheng DL, Xiang YY, Ji LJ, Lu XJ. Competing endogenous RNA interplay in cancer: mechanism, methodology, and perspectives. Tumour Biol (2015) 36:479-88. doi:10.1007/s13277-015-3093-z

107. Kartha RV, Subramanian S. Competing endogenous RNAs (ceRNAs): new entrants to the intricacies of gene regulation. Front Genet (2014) 5:8. doi:10.3389/fgene.2014.00008

108. de Giorgio A, Krell J, Harding V, Stebbing J, Castellano L. Emerging roles of competing endogenous RNAs in cancer: insights from the regulation of PTEN. Mol Cell Biol (2013) 33:3976-82. doi:10.1128/MCB.00683-13

109. Ergun S, Oztuzcu S. Oncocers: ceRNA-mediated cross-talk by sponging miRNAs in oncogenic pathways. Tumour Biol (2015) 36(5):3129-36. doi:10.1007/ s13277-015-3346-x

110. Poliseno L, Salmena L, Zhang J, Carver B, Haveman WJ, Pandolfi PP. A coding-independent function of gene and pseudogene mRNAs regulates tumour biology. Nature (2010) 465:1033-8. doi:10.1038/nature09144

111. Johnsson P, Ackley A, Vidarsdottir L, Lui WO, Corcoran M, Grander D, et al. A pseudogene long-noncoding-RNA network regulates PTEN transcription and translation in human cells. Nat Struct Mol Biol (2013) 20:440-6. doi:10.1038/nsmb.2516

112. Tay Y, Kats L, Salmena L, Weiss D, Tan SM, Ala U, et al. Coding-independent regulation of the tumor suppressor PTEN by competing endogenous mRNAs. Cell (2011) 147:344-57. doi:10.1016/j.cell.2011.09.029

113. Guil S, Esteller M. RNA-RNA interactions in gene regulation: the coding and noncoding players. Trends Biochem Sci (2015) 40:248-56. doi:10.1016/j. tibs.2015.03.001

114. Karreth FA, Tay Y, Perna D, Ala U, Tan SM, Rust AG, et al. In vivo identification of tumor- suppressive PTEN ceRNAs in an oncogenic BRAF-induced mouse model of melanoma. Cell (2011) 147:382-95. doi:10.1016/j.cell.2011.09.032

115. Lee JO, Yang H, Georgescu MM, Di Cristofano A, Maehama T, Shi Y, et al. Crystal structure of the PTEN tumor suppressor: implications for its phosphoinositide phosphatase activity and membrane association. Cell (1999) 99:323-34. doi:10.1016/S0092-8674(00)81663-3

116. Silva A, Yunes JA, Cardoso BA, Martins LR, Jotta PY, Abecasis M, et al. PTEN posttranslational inactivation and hyperactivation of the PI3K/Akt pathway sustain primary T cell leukemia viability. J Clin Invest (2008) 118:3762-74. doi:10.1172/JCI34616

117. Nakahata S, Ichikawa T, Maneesaay P, Saito Y, Nagai K, Tamura T, et al. Loss of NDRG2 expression activates PI3K-AKT signalling via PTEN phosphorylation in ATLL and other cancers. Nat Commun (2014) 5:3393. doi:10.1038/ ncomms4393

118. Yang Z, Yuan XG, Chen J, Luo SW, Luo ZJ, Lu NH. Reduced expression of PTEN and increased PTEN phosphorylation at residue Ser380 in gastric cancer tissues: a novel mechanism of PTEN inactivation. Clin Res Hepatol Gastroenterol (2013) 37:72-9. doi:10.1016/j.clinre.2012.03.002

119. Al-Khouri AM, Ma Y, Togo SH, Williams S, Mustelin T. Cooperative phosphorylation of the tumor suppressor phosphatase and tensin homologue (PTEN) by casein kinases and glycogen synthase kinase 3beta. J Biol Chem (2005) 280:35195-202. doi:10.1074/jbc.M503045200

120. Xu D, Yao Y, Jiang X, Lu L, Dai W. Regulation of PTEN stability and activity by Plk3. J Biol Chem (2010) 285:39935-42. doi:10.1074/jbc.M110.166462

121. Vazquez F, Ramaswamy S, Nakamura N, Sellers WR. Phosphorylation of the PTEN tail regulates protein stability and function. Mol Cell Biol (2000) 20:5010-8. doi:10.1128/MCB.20.14.5010-5018.2000
122. Torres J, Pulido R. The tumor suppressor PTEN is phosphorylated by the protein kinase CK2 at its $\mathrm{C}$ terminus. Implications for PTEN stability to proteasome-mediated degradation. J Biol Chem (2001) 276:993-8. doi:10.1074/ jbc.M009134200

123. Wu Y, Zhou H, Wu K, Lee S, Li R, Liu X. PTEN phosphorylation and nuclear export mediate free fatty acid-induced oxidative stress. Antioxid Redox Signal (2014) 20:1382-95. doi:10.1089/ars.2013.5498

124. Maccario H, Perera NM, Davidson L, Downes CP, Leslie NR. PTEN is destabilized by phosphorylation on Thr366. Biochem J (2007) 405:439-44. doi:10.1042/BJ20061837

125. Xu D, Yao Y, Lu L, Costa M, Dai W. Plk3 functions as an essential component of the hypoxia regulatory pathway by direct phosphorylation of HIF-1alpha. J Biol Chem (2010) 285:38944-50. doi:10.1074/jbc.M110.160325

126. Das S, Dixon JE, Cho W. Membrane-binding and activation mechanism of PTEN. Proc Natl Acad Sci U S A (2003) 100:7491-6. doi:10.1073/ pnas. 0932835100

127. Vazquez F, Matsuoka S, Sellers WR, Yanagida T, Ueda M, Devreotes PN. Tumor suppressor PTEN acts through dynamic interaction with the plasma membrane. Proc Natl Acad Sci U S A (2006) 103:3633-8. doi:10.1073/ pnas. 0510570103

128. Rahdar M, Inoue T, Meyer T, Zhang J, Vazquez F, Devreotes PN. A phosphorylation-dependent intramolecular interaction regulates the membrane association and activity of the tumor suppressor PTEN. Proc Natl Acad Sci U S A (2009) 106:480-5. doi:10.1073/pnas.0811212106

129. Ross AH, Gericke A. Phosphorylation keeps PTEN phosphatase closed for business. Proc Natl Acad Sci U S A (2009) 106:1297-8. doi:10.1073/ pnas.0812473106

130. Bolduc D, Rahdar M, Tu-Sekine B, Sivakumaren SC, Raben D, Amzel LM, et al. Phosphorylation-mediated PTEN conformational closure and deactivation revealed with protein semisynthesis. Elife (2013) 2:e00691. doi:10.7554/ eLife.00691

131. Wu X, Hepner K, Castelino-Prabhu S, Do D, Kaye MB, Yuan XJ, et al. Evidence for regulation of the PTEN tumor suppressor by a membrane-localized multi-PDZ domain containing scaffold protein MAGI-2. Proc Natl Acad Sci U S A (2000) 97:4233-8. doi:10.1073/pnas.97.8.4233

132. Wu Y, Dowbenko D, Spencer S, Laura R, Lee J, Gu Q, et al. Interaction of the tumor suppressor PTEN/MMAC with a PDZ domain of MAGI3, a novel membrane-associated guanylate kinase. J Biol Chem (2000) 275:21477-85. doi:10.1074/jbc.M909741199

133. Tolkacheva T, Boddapati M, Sanfiz A, Tsuchida K, Kimmelman AC, Chan AM. Regulation of PTEN binding to MAGI-2 by two putative phosphorylation sites at threonine 382 and 383. Cancer Res (2001) 61:4985-9.

134. Campbell RB, Liu F, Ross AH. Allosteric activation of PTEN phosphatase by phosphatidylinositol 4,5-bisphosphate. J Biol Chem (2003) 278:33617-20. doi:10.1074/jbc.C300296200

135. Papa A, Wan L, Bonora M, Salmena L, Song MS, Hobbs RM, et al. Cancer-associated PTEN mutants act in a dominant-negative manner to suppress PTEN protein function. Cell (2014) 157:595-610. doi:10.1016/j. cell.2014.03.027

136. Gil A, Andres-Pons A, Fernandez E, Valiente M, Torres J, Cervera J, et al. Nuclear localization of PTEN by a ran-dependent mechanism enhances apoptosis: involvement of an N-terminal nuclear localization domain and multiple nuclear exclusion motifs. Mol Biol Cell (2006) 17:4002-13. doi:10.1091/mbc. E06-05-0380

137. Li Z, Dong X, Wang Z, Liu W, Deng N, Ding Y, et al. Regulation of PTEN by Rho small GTPases. Nat Cell Biol (2005) 7:399-404. doi:10.1038/ncb1236

138. Yim EK, Peng G, Dai H, Hu R, Li K, Lu Y, et al. Rak functions as a tumor suppressor by regulating PTEN protein stability and function. Cancer Cell (2009) 15:304-14. doi:10.1016/j.ccr.2009.02.012

139. Eickholt BJ, Ahmed AI, Davies M, Papakonstanti EA, Pearce W, Starkey $\mathrm{ML}$, et al. Control of axonal growth and regeneration of sensory neurons by the p110d PI 3-kinase. PLoS One (2007) 2:e869. doi:10.1371/journal. pone.0000869

140. Papakonstanti EA, Ridley AJ, Vanhaesebroeck B. The p110d isoform of PI 3-kinase negatively controls RhoA and PTEN. EMBO J (2007) 26:3050-61. doi:10.1038/sj.emboj.7601763

141. Tzenaki N, Aivaliotis M, Papakonstanti EA. FAK phosphorylates PTEN under the control of p1108 PI3 kinase. FASEB J (2015). 
142. Raftopoulou M, Etienne-Manneville S, Self A, Nicholls S, Hall A. Regulation of cell migration by the $\mathrm{C} 2$ domain of the tumor suppressor PTEN. Science (2004) 303:1179-81. doi:10.1126/science.1092089

143. Tibarewal P, Zilidis G, Spinelli L, Schurch N, Maccario H, Gray A, et al. PTEN protein phosphatase activity correlates with control of gene expression and invasion, a tumor-suppressing phenotype, but not with AKT activity. Sci Signal (2012) 5:ra18. doi:10.1126/scisignal.2002138

144. Cho SH, Lee CH, Ahn Y, Kim H, Kim H, Ahn CY, et al. Redox regulation of PTEN and protein tyrosine phosphatases in $\mathrm{H}(2) \mathrm{O}(2)$ mediated cell signaling. FEBS Lett (2004) 560:7-13. doi:10.1016/S0014-5793(04)00112-7

145. Leslie NR, Bennett D, Lindsay YE, Stewart H, Gray A, Downes CP. Redox regulation of PI 3-kinase signalling via inactivation of PTEN. EMBO J (2003) 22:5501-10. doi:10.1093/emboj/cdg513

146. Cao J, Schulte J, Knight A, Leslie NR, Zagozdzon A, Bronson R, et al. Prdx1 inhibits tumorigenesis via regulating PTEN/AKT activity. EMBO J (2009) 28:1505-17. doi:10.1038/emboj.2009.101

147. Lee SR, Yang KS, Kwon J, Lee C, Jeong W, Rhee SG. Reversible inactivation of the tumor suppressor PTEN by $\mathrm{H}_{2} \mathrm{O}_{2}$. J Biol Chem (2002) 277:20336-42. doi:10.1074/jbc.M111899200

148. Hui ST, Andres AM, Miller AK, Spann NJ, Potter DW, Post NM, et al. Txnip balances metabolic and growth signaling via PTEN disulfide reduction. Proc Natl Acad Sci U S A (2008) 105:3921-6. doi:10.1073/pnas.0800293105

149. Meuillet EJ, Mahadevan D, Berggren M, Coon A, Powis G. Thioredoxin-1 binds to the C2 domain of PTEN inhibiting PTEN's lipid phosphatase activity and membrane binding: a mechanism for the functional loss of PTEN's tumor suppressor activity. Arch Biochem Biophys (2004) 429:123-33. doi:10.1016/j. abb.2004.04.020

150. Okumura K, Mendoza M, Bachoo RM, Depinho RA, Cavenee WK, Furnari FB. PCAF modulates PTEN activity. J Biol Chem (2006) 281:26562-8. doi:10.1074/jbc.M605391200

151. Ding L, Chen S, Liu P, Pan Y, Zhong J, Regan KM, et al. CBP loss cooperates with PTEN haploinsufficiency to drive prostate cancer: implications for epigenetic therapy. Cancer Res (2014) 74:2050-61. doi:10.1158/0008-5472. CAN-13-1659

152. Chae HD, Broxmeyer HE. SIRT1 deficiency downregulates PTEN/JNK/ FOXO1 pathway to block reactive oxygen species-induced apoptosis in mouse embryonic stem cells. Stem Cells Dev (2011) 20:1277-85. doi:10.1089/ scd.2010.0465

153. Trotman LC, Wang X, Alimonti A, Chen Z, Teruya-Feldstein J, Yang H, et al. Ubiquitination regulates PTEN nuclear import and tumor suppression. Cell (2007) 128:141-56. doi:10.1016/j.cell.2006.11.040

154. Wang X, Trotman LC, Koppie T, Alimonti A, Chen Z, Gao Z, et al. NEDD4-1 is a proto-oncogenic ubiquitin ligase for PTEN. Cell (2007) 128:129-39. doi:10.1016/j.cell.2006.11.039

155. Amodio N, Scrima M, Palaia L, Salman AN, Quintiero A, Franco R, et al. Oncogenic role of the E3 ubiquitin ligase NEDD4-1, a PTEN negative regulator, in non-small-cell lung carcinomas. Am J Pathol (2010) 177:2622-34. doi:10.2353/ajpath.2010.091075

156. Fouladkou F, Landry T, Kawabe H, Neeb A, Lu C, Brose N, et al. The ubiquitin ligase Nedd4-1 is dispensable for the regulation of PTEN stability and localization. Proc Natl Acad Sci U S A (2008) 105:8585-90. doi:10.1073/ pnas. 0803233105

157. Eide PW, Cekaite L, Danielsen SA, Eilertsen IA, Kjenseth A, Fykerud TA, et al. NEDD4 is overexpressed in colorectal cancer and promotes colonic cell growth independently of the PI3K/PTEN/AKT pathway. Cell Signal (2013) 25:12-8. doi:10.1016/j.cellsig.2012.08.012

158. van Themsche C, Leblanc V, Parent S, Asselin E. X-linked inhibitor of apoptosis protein (XIAP) regulates PTEN ubiquitination, content, and compartmentalization. J Biol Chem (2009) 284:20462-6. doi:10.1074/jbc.C109.009522

159. Maddika S, Kavela S, Rani N, Palicharla VR, Pokorny JL, Sarkaria JN, et al. WWP2 is an E3 ubiquitin ligase for PTEN. Nat Cell Biol (2011) 13:728-33. doi: $10.1038 / \mathrm{ncb} 2240$

160. Lee JT, Shan J, Zhong J, Li M, Zhou B, Zhou A, et al. RFP-mediated ubiquitination of PTEN modulates its effect on AKT activation. Cell Res (2013) 23:552-64. doi:10.1038/cr.2013.27

161. Ahmed SF, Deb S, Paul I, Chatterjee A, Mandal T, Chatterjee U, et al. The chaperone-assisted E3 ligase $\mathrm{C}$ terminus of Hsc70-interacting protein (CHIP) targets PTEN for proteasomal degradation. J Biol Chem (2012) 287:15996-6006. doi:10.1074/jbc.M111.321083
162. Song MS, Salmena L, Carracedo A, Egia A, Lo-Coco F, Teruya-Feldstein J, et al. The deubiquitinylation and localization of PTEN are regulated by a HAUSP-PML network. Nature (2008) 455:813-7. doi:10.1038/nature07290

163. Gonzalez-Santamaria J, Campagna M, Ortega-Molina A, Marcos-Villar L, De La Cruz-Herrera CF, Gonzalez D, et al. Regulation of the tumor suppressor PTEN by SUMO. Cell Death Dis (2012) 3:e393. doi:10.1038/cddis. 2012.135

164. Huang J, Yan J, Zhang J, Zhu S, Wang Y, Shi T, et al. SUMO1 modification of PTEN regulates tumorigenesis by controlling its association with the plasma membrane. Nat Commun (2012) 3:911. doi:10.1038/ncomms1919

165. Bassi C, Ho J, Srikumar T, Dowling RJ, Gorrini C, Miller SJ, et al. Nuclear PTEN controls DNA repair and sensitivity to genotoxic stress. Science (2013) 341:395-9. doi:10.1126/science. 1236188

166. Sanchez T, Thangada S, Wu MT, Kontos CD, Wu D, Wu H, et al. PTEN as an effector in the signaling of antimigratory $\mathrm{G}$ protein-coupled receptor. Proc Natl Acad Sci U S A (2005) 102:4312-7. doi:10.1073/pnas.0409784102

167. Cao J, Wan L, Hacker E, Dai X, Lenna S, Jimenez-Cervantes C, et al. MC1R is a potent regulator of PTEN after UV exposure in melanocytes. Mol Cell (2013) 51:409-22. doi:10.1016/j.molcel.2013.08.010

168. Lin HK, Hu YC, Lee DK, Chang C. Regulation of androgen receptor signaling by PTEN (phosphatase and tensin homolog deleted on chromosome 10) tumor suppressor through distinct mechanisms in prostate cancer cells. Mol Endocrinol (2004) 18:2409-23. doi:10.1210/me.2004-0117

169. Rosenkranz AA, Slastnikova TA, Durymanov MO, Sobolev AS. Malignant melanoma and melanocortin 1 receptor. Biochemistry (Mosc) (2013) 78:1228-37. doi:10.1134/S0006297913110035

170. He L, Fan C, Kapoor A, Ingram AJ, Rybak AP, Austin RC, et al. Alphamannosidase 2C1 attenuates PTEN function in prostate cancer cells. Nat Commun (2011) 2:307. doi:10.1038/ncomms1309

171. Gorbenko O, Panayotou G, Zhyvoloup A, Volkova D, Gout I, Filonenko V. Identification of novel PTEN-binding partners: PTEN interaction with fatty acid binding protein FABP4. Mol Cell Biochem (2010) 337:299-305. doi:10.1007/s11010-009-0312-1

172. van Diepen MT, Parsons M, Downes CP, Leslie NR, Hindges R, Eickholt BJ. MyosinV controls PTEN function and neuronal cell size. Nat Cell Biol (2009) 11:1191-6. doi:10.1038/ncb1961

173. Mistafa O, Ghalali A, Kadekar S, Hogberg J, Stenius U. Purinergic receptor-mediated rapid depletion of nuclear phosphorylated Akt depends on pleckstrin homology domain leucine-rich repeat phosphatase, calcineurin, protein phosphatase 2A, and PTEN phosphatases. J Biol Chem (2010) 285:27900-10. doi:10.1074/jbc.M110.117093

174. von Stein W, Ramrath A, Grimm A, Muller-Borg M, Wodarz A. Direct association of Bazooka/PAR-3 with the lipid phosphatase PTEN reveals a link between the PAR/aPKC complex and phosphoinositide signaling. Development (2005) 132:1675-86. doi:10.1242/dev.01720

175. Tamura M, Gu J, Danen EHJ, Takino T, Miyamoto S, Yamada KM. PTEN interactions with focal adhesion kinase and suppression of the extracellular matrix-dependent phosphatidylinositol 3-kinase/Akt cell survival pathway. J Biol Chem (1999) 274:20693-703. doi:10.1074/jbc.274.29.20693

176. Haier J, Nicolson GL. PTEN regulates tumor cell adhesion of colon carcinoma cells under dynamic conditions of fluid flow. Oncogene (2002) 21:1450-60. doi:10.1038/sj.onc. 1205213

177. Mehenni H, Lin-Marq N, Buchet-Poyau K, Reymond A, Collart MA, Picard D, et al. LKB1 interacts with and phosphorylates PTEN: a functional link between two proteins involved in cancer predisposing syndromes. Hum Mol Genet (2005) 14:2209-19. doi:10.1093/hmg/ddi225

178. Li Z, Jiang H, Xie W, Zhang Z, Smrcka AV, Wu D. Roles of PLC-b2 and -b3 and PI3Kg in chemoattractant-mediated signal transduction. Science (2000) 287:1046-9. doi:10.1126/science.287.5455.1046

179. Kotelevets L, Van Hengel J, Bruyneel E, Mareel M, Van Roy F, Chastre E. Implication of the MAGI-1b/PTEN signalosome in stabilization of adherens junctions and suppression of invasiveness. FASEB J (2005) 19:115-7. doi:10.1096/f.04-1942fje

180. Sotelo NS, Valiente M, Gil A, Pulido R. A functional network of the tumor suppressors APC, hDlg, and PTEN, that relies on recognition of specific PDZ-domains. J Cell Biochem (2012) 113:2661-70. doi:10.1002/jcb.24141

181. Adey NB, Huang L, Ormonde PA, Baumgard ML, Pero R, Byreddy DV, et al. Threonine phosphorylation of the MMAC1/PTEN PDZ binding domain both inhibits and stimulates PDZ binding. Cancer Res (2000) 60:35-7. 
182. Valiente M, Andres-Pons A, Gomar B, Torres J, Gil A, Tapparel C, et al. Binding of PTEN to specific PDZ domains contributes to PTEN protein stability and phosphorylation by microtubule-associated serine/threonine kinases. J Biol Chem (2005) 280:28936-43. doi:10.1074/jbc.M504761200

183. Caselli A, Mazzinghi B, Camici G, Manao G, Ramponi G. Some protein tyrosine phosphatases target in part to lipid rafts and interact with caveolin-1. Biochem Biophys Res Commun (2002) 296:692-7. doi:10.1016/ S0006-291X(02)00928-2

184. Lin MC, Liu YC, Tam MF, Lu YJ, Hsieh YT, Lin LY. PTEN interacts with metal-responsive transcription factor 1 and stimulates its transcriptional activity. Biochem J (2012) 441:367-77. doi:10.1042/BJ20111257

185. Freeman DJ, Li AG, Wei G, Li HH, Kertesz N, Lesche R, et al. PTEN tumor suppressor regulates $\mathrm{p} 53$ protein levels and activity through phosphatase-dependent and -independent mechanisms. Cancer Cell (2003) 3:117-30. doi:10.1016/S1535-6108(03)00021-7

186. Yang C, LiS, Wang M, Chang AK, Liu Y,Zhao F, et al. PTEN suppresses the oncogenic function of AIB1 through decreasing its protein stability via mechanism involving Fbw7 alpha. Mol Cancer (2013) 12:21. doi:10.1186/1476-4598-12-21

187. Teicher BA. Transforming growth factor-beta and the immune response to malignant disease. Clin Cancer Res (2007) 13:6247-51. doi:10.1158/10780432.CCR-07-1654

188. Hjelmeland AB, Hjelmeland MD, Shi Q, Hart JL, Bigner DD, Wang XF, et al. Loss of phosphatase and tensin homologue increases transforming growth factor beta-mediated invasion with enhanced SMAD3 transcriptional activity. Cancer Res (2005) 65:11276-81. doi:10.1158/0008-5472.CAN-05-3016

189. Fan C, He L, Kapoor A, Rybak AP, De Melo J, Cutz JC, et al. PTEN inhibits BMI1 function independently of its phosphatase activity. Mol Cancer (2009) 8:98. doi:10.1186/1476-4598-8-98

190. Kim YJ, Park SJ, Choi EY, Kim S, Kwak HJ, Yoo BC, et al. PTEN modulates miR-21 processing via RNA-regulatory protein RNH1. PLoS One (2011) 6:e28308. doi:10.1371/journal.pone.0028308

191. Shen WH, Balajee AS, Wang J, Wu H, Eng C, Pandolfi PP, et al. Essential role for nuclear PTEN in maintaining chromosomal integrity. Cell (2007) 128:157-70. doi:10.1016/j.cell.2006.11.042

192. Li M, Zhang P. The function of APC/CCdh1 in cell cycle and beyond. Cell Div (2009) 4:2. doi:10.1186/1747-1028-4-2

193. Song MS, Carracedo A, Salmena L, Song SJ, Egia A, Malumbres M, et al. Nuclear PTEN regulates the APC-CDH1 tumor-suppressive complex in a phosphatase-independent manner. Cell (2011) 144:187-99. doi:10.1016/j. cell.2010.12.020

194. He L, Ingram A, Rybak AP, Tang D. Shank-interacting protein-like 1 promotes tumorigenesis via PTEN inhibition in human tumor cells. J Clin Invest (2010) 120:2094-108. doi:10.1172/JCI40778

195. Okahara F, Ikawa H, Kanaho Y, Maehama T. Regulation of PTEN phosphorylation and stability by a tumor suppressor candidate protein. J Biol Chem (2004) 279:45300-3. doi:10.1074/jbc.C400377200

196. Bononi A, Pinton P. Study of PTEN subcellular localization. Methods (2015) 7(7-78):92-103. doi:10.1016/j.ymeth.2014.10.002

197. Walker SM, Leslie NR, Perera NM, Batty IH, Downes CP. The tumour-suppressor function of PTEN requires an N-terminal lipid-binding motif. Biochem J (2004) 379:301-7. doi:10.1042/BJ20031839

198. Redfern RE, Redfern D, Furgason ML, Munson M, Ross AH, Gericke A. PTEN phosphatase selectively binds phosphoinositides and undergoes structural changes. Biochemistry (2008) 47:2162-71. doi:10.1021/bi702114w

199. Niedermeier M, Hennessy BT, Knight ZA, Henneberg M, Hu J, Kurtova $\mathrm{AV}$, et al. Isoform-selective phosphoinositide 3'-kinase inhibitors inhibit CXCR4 signaling and overcome stromal cell-mediated drug resistance in chronic lymphocytic leukemia: a novel therapeutic approach. Blood (2009) 113:5549-57. doi:10.1182/blood-2008-06-165068

200. Lindsay Y, Mccoull D, Davidson L, Leslie NR, Fairservice A, Gray A, et al. Localization of agonist-sensitive PtdIns(3,4,5)P3 reveals a nuclear pool that is insensitive to PTEN expression. J Cell Sci (2006) 119:5160-8. doi:10.1242/ jcs.000133

201. Li P, Wang D, Li H, Yu Z, Chen X, Fang J. Identification of nucleolus-localized PTEN and its function in regulating ribosome biogenesis. Mol Biol Rep (2014) 41:6383-90. doi:10.1007/s11033-014-3518-6

202. Denning G, Jean-Joseph B, Prince C, Durden DL, Vogt PK. A short $\mathrm{N}$-terminal sequence of PTEN controls cytoplasmic localization and is required for suppression of cell growth. Oncogene (2007) 26:3930-40. doi:10.1038/sj.onc.1210175

203. Mossink MH, Van Zon A, Scheper RJ, Sonneveld P, Wiemer EA. Vaults: a ribonucleoprotein particle involved in drug resistance? Oncogene (2003) 22:7458-67. doi:10.1038/sj.onc.1206947

204. Yu Z, Fotouhi-Ardakani N, Wu L, Maoui M, Wang S, Banville D, et al. PTEN associates with the vault particles in HeLa cells. J Biol Chem (2002) 277:40247-52. doi:10.1074/jbc.M207608200

205. Chung JH, Ginn-Pease ME, Eng C. Phosphatase and tensin homologue deleted on chromosome 10 (PTEN) has nuclear localization signal-like sequences for nuclear import mediated by major vault protein. Cancer Res (2005) 65:4108-16. doi:10.1158/0008-5472.CAN-05-0124

206. Liu F, Wagner S, Campbell RB, Nickerson JA, Schiffer CA, Ross AH. PTEN enters the nucleus by diffusion. J Cell Biochem (2005) 96:221-34. doi:10.1002/ jcb. 20525

207. Liang H, He S, Yang J, Jia X, Wang P, Chen X, et al. PTENalpha, a PTEN isoform translated through alternative initiation, regulates mitochondrial function and energy metabolism. Cell Metab (2014) 19:836-48. doi:10.1016/j. cmet.2014.03.023

208. Zhu Y, Hoell P, Ahlemeyer B, Krieglstein J. PTEN: a crucial mediator of mitochondria-dependent apoptosis. Apoptosis (2006) 11:197-207. doi:10.1007/ s10495-006-3714-5

209. Bononi A, Bonora M, Marchi S, Missiroli S, Poletti F, Giorgi C, et al. Identification of PTEN at the ER and MAMs and its regulation of $\mathrm{Ca}(2+)$ signaling and apoptosis in a protein phosphatase-dependent manner. Cell Death Differ (2013) 20:1631-43. doi:10.1038/cdd.2013.77

210. Patergnani S, Suski JM, Agnoletto C, Bononi A, Bonora M, De Marchi E, et al. Calcium signaling around mitochondria associated membranes (MAMs). Cell Commun Signal (2011) 9:19. doi:10.1186/1478-811X-9-19

211. Giorgi C, Baldassari F, Bononi A, Bonora M, De Marchi E, Marchi S, et al. Mitochondrial $\mathrm{Ca}(2+)$ and apoptosis. Cell Calcium (2012) 52:36-43. doi:10.1016/j.ceca.2012.02.008

212. Hopkins BD, Fine B, Steinbach N, Dendy M, Rapp Z, Shaw J, et al. A secreted PTEN phosphatase that enters cells to alter signaling and survival. Science (2013) 341:399-402. doi:10.1126/science.1234907

213. Putz U, Howitt J, Doan A, Goh CP, Low LH, Silke J, et al. The tumor suppressor PTEN is exported in exosomes and has phosphatase activity in recipient cells. Sci Signal (2012) 5:ra70. doi:10.1126/scisignal.2003084

214. Howitt J, Lackovic J, Low LH, Naguib A, Macintyre A, Goh CP, et al. Ndfip1 regulates nuclear Pten import in vivo to promote neuronal survival following cerebral ischemia. J Cell Biol (2012) 196:29-36. doi:10.1083/jcb.201105009

Conflict of Interest Statement: The authors declare that the research was conducted in the absence of any commercial or financial relationships that could be construed as a potential conflict of interest.

Copyright (c) 2015 Bermúdez Brito, Goulielmaki and Papakonstanti. This is an open-access article distributed under the terms of the Creative Commons Attribution License (CC BY). The use, distribution or reproduction in other forums is permitted, provided the original author(s) or licensor are credited and that the original publication in this journal is cited, in accordance with accepted academic practice. No use, distribution or reproduction is permitted which does not comply with these terms. 